Revista Complutense de Historia de América

ISSN: $1132-8312$

http://dx.doi.org/10.5209/RCHA.56732

\title{
Luzes e sombras: a censura de livros na capitania da Bahia $(1811-1821)^{1}$
}

\author{
Pablo Antonio Iglesias Magalhães ${ }^{2}$
}

Recibido: 5 de octubre de 2015 / Aceptado: 23 de diciembre de 2015

Resumo. O presente artigo revela o estabelecimento de uma Comissão de Censura de impressos na capitania da Bahia, no Brasil. que funcionou entre 1811 e 1821. Foi investigado seu processo de implantação, bem como aspectos biográficos e políticos dos censores e, por meio de 44 cartas existentes no Arquivo Público do Estado da Bahia, os manuscritos que foram submetidos à referida Comissão. A instituição é desconhecida pela historiografia luso-brasileira e apresenta novas informações acerca da Capitania da Bahia às vésperas da Guerra da Independência.

Palavras-chave: Censura; tipografia de Manoel Antonio da Silva Serva; maçonaria; Brasil colonial; siglo XIX.

[en] Enlightenment and Darkness: Censorship of Books in the Captaincy of Bahía (1811-1821)

\begin{abstract}
This article reveals the establishment of a Censorship Committee of printed matter, which functioned between 1811 and 1821 in the Captaincy of Bahia, in Brazil. The Committee's implementation process is investigated, as well as certain biographical and political aspects of the censors. In addition, the manuscripts submitted to the Committee have also been studied, by virtue of 44 existing letters from the Arquivo Público do Estado da Bahia. The institution, as of yet unknown in Luso-Brazilian History, reveals new information about the Captaincy of Bahia on the eve of the War of Independence. Keywords: Censorship; Typography of Manoel Antonio da Silva Serva; Masonry; Colonial Brazil; 19th Century.
\end{abstract}

Sumario. 1. A criação da censura na Bahia. 2. Os censores bahienses. 3. As obras censuradas. 4. Referências bibliográficas. 5. Anexos: Cartas do Governo para os censores.

Cómo citar: Iglesias Magalhães, P.A. (2017) Luzes e sombras: a censura de libros na capitania da Bahia (1811-1821), en Revista Complutense de Historia de América 43, 203-236.

\section{A criação da censura na Bahia}

Quando se faz luz, pode-se criar também sombras. Essa dicotomia está presente na gênese da imprensa na Capitania da Bahia, estabelecida em maio de 1811. A impressão de livros fora, até então, proibida pelas autoridades portuguesas. Decerto que

1 Este trabajo se integra en el proyecto de investigación HAR2012-37560-CO2-01, Conservación de la Monarquía y equilibrio europeo en los siglos XVII-XVIII.

2 Universidade Federal do Oeste da Bahia (UFOB) (Brasil)

Email: pimagalhaes@yahoo.com.br 
a instalação de uma tipografia na cidade do Salvador transformou a cena política e cultural daquele tempo, permitindo a circulação do primeiro jornal da Bahia, a Idade d'Ouro do Brazil (1811-1822), de compendios didáticos e livros de diversos gêneros literários, que antes precisavam ser trazidos da Europa ou do Rio de Janeiro.

Àquele período, os livros impressos eram anunciados nos jornais portugueses sempre com os títulos antecedido da expressão "saiu à luz", associando o objeto à ideia do nascimento, bem como de instrumento da Ilustração. Antes de sair à luz, contudo, os livros luso-brasílicos precisavam vencer as sombras da censura. A História da censura dos livros em Portugal é conhecida pelos historiadores, na medida em que há importantes estudos a contemplar o tema. José Timóteo da Silva Bastos assinala que a censura de impressos em Portugal teve início a 22 de janeiro de 1537, reunindo o Santo Ofício, o Ordinário (autoridade episcopal) e o Desembargo do Paço (autoridade régia) ${ }^{3}$. O ministério pombalino (1750-1775) estabeleceu mudanças no sistema português de censura e em 5 de abril 1768 foi instituída a Real Mesa Censória, por ordem do Marquês de Pombal, que unificou o sistema censório anteriormente dividido em três partes. Em 1787, D. Maria I reformou novamente a censura, constituindo a Comissão Geral para o Exame e a Censura dos Livros, que funcionou até 17 de dezembro de 1794. A partir dessa data, o exame e censura dos livros voltou a ser exercido pelo Santo Oficio, pelo Desembargo do Paço e pela autoridade episcopal. Em 1821 a censura aos escritos passa a ser de responsabilidade do Desembargo do Paço e do Ordinário, já que em Portugal o Tribunal do Santo Ofício foi extinto em definitivo.

As monarquias europeias, no geral, mantiveram algum tipo de aparato censório ao tempo em que os livros da Ilustração questionavam os fundamentos ideológicos do Antigo Regime. Portugal não foi uma exceção, mas, ao contrário da Espanha que precocemente instalou Tribunais do Santo Ofício nas colônias americanas, a Coroa lusitana manteve a censura centralizada na metrópole até o início do século XIX. Exceção à essa centralidade do aparato censorial de Portugal foram os livros impressos em parques tipográficos de origem portuguesa em Goa, Macau e no Japão, entre os séculos XVI e XVII. A imensa maioria dos autores e tradutores brasílicos, contudo, entre os séculos XVII e XVIII, tiveram que imprimir suas obras em Lisboa, no Porto ou em Coimbra submetendo seus manuscritos aos censores do Reino.

A mudança da Corte para o Brasil, em fins 1807, acarretou na transposição das instituições lusas para o Atlântico sul, bem como no estabelecimento da Impressão Régia no Rio de Janeiro. Foi estabelecida, por Alvará Régio em 22 de abril de 1808, a Mesa do Desembargo do Paço no Rio de Janeiro, formada por religiosos e leigos egressos da Universidade de Coimbra, que teve como objetivo acolher solicitações de licença e autorização as mais variadas. A provisão de 14 de outubro de 1808 acrescentou a obrigação de controlar o despacho de livros e papéis que passassem pelas alfândegas. Márcia Abreu observou que "à revelia da junta diretora da também recém-criada Imprensa Régia, a Mesa do Desembargo do Paço conquistou o direito de exercer a censura prévia sobre os textos destinados à publicação, passando a competir-lhe o exame dos escritos submetidos à casa impresora"4. Foi constituída, por essa via, uma Comissão de Censura no Rio de Janeiro, seguindo-se à instalação da Impressão Régia, que já foi contemplada com estudos sobre o funcionamento do

Silva Bastos, 1926: 47-60.

Abreu, 2002: 4-5. 
seu aparato burocrático e jurídico, realizados pelas historiadoras Lucia Maria Bastos Neves, Leila Algranti e Márcia Abreu. Os primeiros censores régios indicados para a nova capital do Império português foram frei Antônio da Arrábida, o padre-mestre João Manzoni, Luís José de Carvalho e Melo e, por fim, José da Silva Lisboa. Assim, é possível afirmar que o aparato burocrático da censura de livros também foi transportado de Portugal para as suas duas principais cidades no Atlântico sul.

A historiografia luso-brasileira, contudo, desconhece que também foi estabelecida uma política de censura de livros na Capitania da Bahia entre 1811 e 1821. Exceção, diga-se, é o estudo de Berbert de Castro sobre a Tipografia de Manoel Antonio da Silva Serva (1811-1819), no qual identificou alguns registros da censura naquela parte do Império ultramarino português ${ }^{5}$. O presente artigo investiga a formação e o desenvolvimento da Comissão de Censura na Bahia, a partir da constituição do seu aparato jurídico e burocrático, apresentando também os títulos dos manuscritos que foram submetidos aos censores. Apesar de existir por um período relativamente efêmero de dez anos, o estudo desse mecanismo de censura revela muito do panorama cultural e político da referida capitania na década que antecedeu a guerra pela Independência (1822-1823).

Além do ineditismo do assunto, o problema que se impõe é demonstrar que a Comissão de Censura na Bahia tem a peculiaridade de ser formada por homens de espírito liberal, suspeitos de serem pedreiros-livres, sendo que alguns deles eram acusados de comungarem "os abomináveis princípios franceses". A maçonaria, então, era condenada pela Igreja Católica por via da Bula In Eminenti (1738) do papa Clemente VII e do Breve Providus (1751), do papa Bento XIV. Assim, a hipótese que se impõe é a de que a composição da Comissão de Censura na Bahia possibilitou a publicação de obras de orientação política liberal, na medida em que seus membros aceitaram até mesmo a publicação de livros proibidos em Portugal.

As particularidades da censura de livros na Bahia podem ser compreendidas, principalmente, a partir do exame da correspondência entre o governo da capitania e as autoridades censoriais. O registro da censura de livros na Bahia foi preservado na coleção de Correspondência do Governo para Diversas Autoridades, que integra a seção Colonial do Arquivo Público do Estado da Bahia. As cartas dos governadores tratando da censura, estabelecendo seus mecanismos e remetendo os manuscritos para os membros da Comissão de Censura estão dispersos em seis códices manuscritos que abrangem o período de uma década, a começar em 1811, ano do estabelecimento da imprensa na Bahia ${ }^{6}$.

A intenção de criar uma Comissão de Censura na Bahia já estava declarada em 1810, no requerimento para estabelecer a primeira tipografia naquela capitania, de autoria do negociante português Manoel Antonio da Silva Serva:

E pois que huma tal empreza hé inteiramente nova, nesta Cidade e mesmo nesta parte do Brazil, para que ella possa produzir o dezejado effeito, e empregar-se com vantagem do publico, e do particular, convirá de pôr, es estabelecer em regra o modo de licenciamento dos Livros, e papeis que se queiram aqui imprimir, e

Castro, 1969: 21-28.

6 Arquivo Público do Estado da Bahia [Brasil] (em diante APEB), Colonial/Provincial, Correspondência do Governo para Diversas Autoridades, maços 166 (1809-1811), 167 (1810-1811), 168 (1811-1814), 169 (18141817), 170 (1817-1819), 172-E, (1819-1820) 173 (1820-1821). 
publicar por meio do prélo.

Em consequencia por tanto: O Supplicante se permitte de lembrar, o que a este respeto se pratica nas Cidades do Porto, e de Coimbra, ou quando este meio não pareça conveniente, outro qualquer que á Sua Alteza Real Aprouver de Mandar; sendo certo, que o Concurso da Authoridade Pontificia, Real, e Epsicopal, que a Carta de Ley de 17 de Dezembro de 1794 precréve, como indispensavelmente necessario para a Censura, Revizão, e Licenciamento dos Livros, se pode exercitar nesta Cidade pelo Governo, e pelo Prelado Ordinario, deputando tanto este, como aquelle, certo numero de Censores, que encarregados de escrupulosa revizão de todos os Livros, e papeis, que se quizerem offercer ao prélo dê lugar pelas suas Censuras à admissão, ou repulsa da impressão, e publicação dos livros, e papeis offerecidos; regulando-se o Systema dos Censores, e dos licenciamentos, pelo que se Dettermina no Regimento da extinta Meza Censoria de 5 de Abril de 1768, pelo disposto da dita Carta de Ley de 17 de Dezembro de 1794, e pelo mais a este respeito, ordemnado à Meza do Dezembargo do Paço.

O Supplicante espera, que Vossa Excelencia se Dignará de tomar em Consideração o que tem tido a honra de reprezentar, e expôr a Vossa Excelencia, à cuja Penetração, e Luzes não escapará a importancia do Negocio, e os bons dezejos do Supplicante.

Bahia, 18 de Dezembro de $1810^{7}$.

A documentação conservada no Rio de Janeiro e na Bahia permite acompanhar os trâmites para a implantação da Comissão de Censura, efetivamente estabelecida pela Carta Régia de 5 de fevereiro de 1811. Nela se declara que os censores devem obedecer:

Conde dos Arcos Governador e Capitão da Capitania da Bahia, Amigo. Eu o Principe Regente vos Envio muito Saudar, como aquelle que Amo. Sendo-Me presente a vossa Reprezentação de vinte e quatro de Dezembro do anno passado, sobre o Requerimento de Manoel Antonio da Silva Serva Negociante dessa Praça, que pretende estabelecer nella huma Tipografia para a qual tem já prontos os caracteres, prelos, e mais utensis necessarios a fim de imprimir todos os escritos, que se lhe apresentarem com as competentes, e precisas approvaçoens, e faculdades, e reimprimir os que já correm impressos; e Dezejando promover, e adiantar o estabelecimento de todas as Artes, e Manufacturas neste Estado para prosperar a Industria Nacional, por cujo motivo já houve por bem levantar as prohibiçoens, que existião, promulgando o Alvará de primeiro de Abril de oito centos e oito; e tendo a da Tipografia além desta razão geral e commum a todas a especial, e mui vantajoza da utilidade, que ao bem publico resulta de se diffundirem, e derramarem os conhecimentos humanos, facilitando-se assim o estudo de todas as Sciencias, e Artes, e de todo o genero de literatura; e tornando-se por este meio os Meus fieis Vassallos mais dignos, e uteis a Patria, a si, e aos seus concidadoens, e mais capazes de concorrer para a publica felicidade: Sou Servido facultar o referido Manoel Antonio da Silva Serva a necessaria permissão de estabelecer a Tipografia, que pretende erigir com a denominação de Serva: E Attendendo a que supposto

Requerimento de Manoel Antonio da Silva Serva ao Príncipe Regente. Bahia, 18-XII-1810. Arquivo Nacional do Rio Janeiro [Brasil] (em diante ANRJ), Ofícios do Governo da Bahia, Livro 3 (1810), ff. 145-146. 
não convenha acanhar, e restringir as produçoens do espirito, e entendimento, estancando o progresso das Sciencias e Literaturas com tudo a liberdade ilimitada de pensar, e de escrever pode perverter o espirito publico, e corromper a moral, e os costumes, estabelecendo maximas prejudiciaes a cada hum dos Meus fieis Vassalos, e ao socego, e publica tranquilidade; E querendo facilitar o trabalho, e adiantamento da referida Imprensa: Hei outro sim por bem, que nenhum manuscrito e possa imprimir, ou qualquer Livro reimprimir nesta Tipografia sem licença vossa, de accordo com o Reverendo Arcebispo dessa Diocese, a qual não será concedida sem que primeiro sejão revistos, e approvados por Censores, que vos nomeareis d'entre as pessoas, que julgardes capazes por seus conhecimentos, e probidade, e o Reverendo Arcebispo d'entre os Ecclesiasticos de avantajado saber, e bem morigerado costumes; e quando acontecer não ser o vosso parecer conforme o do Prelado prevalecerá o delle nas materias Theologicas, e Ecclesiasticas, e o vosso em todas as outras. E vos regulareis ambos, e os Censores pelas regras ampla, e circunstaciadamente espebelecida pelo Alvará de desesete de Desembro de mil sete sentos noventa e quatro, imprimindo-se sempre em todos os Exemplares o ultimo despacho da permissão concedida para a imprensa, a qual nunca concedereis para se reimprimir se houver pivilegio exclusivo facultado ao primeiro Editor. $\mathrm{O}$ que cumprireis com o zelo, e honra com que vos empregais no Meu Real Serviço, e como convém em negocio em que tanto interessa o bem publico, e a tranquilidade, e prosperidadedos Meus Fieis Vassallos. Escrita no Palacio do Rio de Janeiro aos cinco de Fevereiro de mil oito centos e onze.

Para o Conde dos Arcos

PRINCIPE.

Cumpra-se e registre-se, expedindo-se as ordens necessarias.

Bahia 11 de Abril de 1811. Conde dos $\operatorname{Arcos}^{8}$.

Conforme o documento acima transcrito, a censura na Bahia ficava subordinada às determinações contidas no Alvará de 17 de dezembro de 1794. A principal diferença consiste na inexistência de tribunais do Santo Ofício no Brasil, fazendo com que a Comissão de Censura fosse orientada somente pela censura régia e episcopal, sendo os censores nomeados pelo governador D. Marcos de Noronha e Brito, o oitavo Conde dos Arcos, e pelo arcebispo D. José de Santa Escolástica Alvarez Pereira (1804-1813). Deve-se sublinhar que o alvará de 17 de dezembro de 1794 foi feito sob o assombro da Revolução Francesa (1789), registrando, por essa razão, no corpo do seu texto a preocupação com "a extraordinária, e temível revolução literária de doutrinal que nestes últimos anos [está] propagando novos, inauditos e horrorosos princípios, e sentimentos políticos, filosóficos, ideológicos e jurídicos derramados e disseminados para a ruína da religião, dos impérios e da sociedade". Ordenava, em seguida, prudência política e religiosa contra a propagação dos princípios filosóficos oriundos da França. O Alvará de 17 de dezembro de 1794 definira que a censura à produção, à circulação, à leitura e à posse de livros deveria pautar-se por vinte e cinco condições, estabelecidas no regimento da Real Mesa, que proibiam escritos contra a religião ou a teologia católica (dezoito condições) e contra a política régia (sete condições).

Carta Régia para o Governador Conde dos Arcos. Rio de Janeiro, 05-II-1811. APEB, Colonial/Provincial, Ordens Régias, (1810-1812), ff. 163-164. 
Percebe-se, por outro viés, no documento acima, uma preocupação da monarquia com a difusão dos conhecimentos por meio de obras científicas e literárias. Isso pode ser assinalado como reflexo de uma política ilustrada que foi fortalecida durante o ministério de D. Rodrigo de Sousa Coutinho, ministro e secretário de Estado da Marinha e Domínios Ultramarinos em Portugal e depois no Brasil (1808-1812). Anglófilo e progressista, D. Rodrigo já estimulara a difusão das ciências em Portugal, como pode ser percebido no financiamento público à Tipografia do Arco do Cego (1799-1801), dirigida por frei José Mariano da Conceição Veloso. Também no seu ministério, a Real Academia de Ciências de Lisboa publicou uma importante série de memórias econômicas, da qual participaram autores brasílicos daquela agremiação, nas quais estava associada a ideia de que o crescimento econômico do Reino e do Ultramar era possível mediante a difusão do pensamento científico e das técnicas de produção. Decerto que a imprensa era uma ferramenta necessária ao governo português no desenvolvimento da economia.

Após receber a ordem régia, acima transcrita, o Conde dos Arcos emitiu um aviso para o tipógrafo Serva informando-lhe das disposições nela contida:

\begin{abstract}
P.a Manoel Antonio da Silva Serva
Sendo o Principe Nosso Sr. Servido, por Carta Regia, de 5 de Fevereiro do Prezente anno., facultar a VM.ce a necessaria permissão de estabelecer a Tipografia, que pretende erigir nesta Cid.e com a denominação de Serva, e Havendo outrosim por bem, Ordenar a forma porque se deve regular este estabelecim.to Previno VM.ce, de que nenhum manuscrito possa imprimir, ou qualquer Livro reimprimir, nessa Tipografia, sem proceder Licença minha, de acordo com o Reverendo Bispo desta Diocese, imprimindo-se sempre em todos os Exemplares, o ultimo Despacho da permisão concedida, para a Imprensa; na intelligencia de que, não poderá reimprimir obra alguma, para a qual haja Privilegio exclusivo, facultando ao primeiro Editor; e de todas mais que na sobredita forma imprimir, ou reimprimir, enviará sempre hum Exemplar, para a Secretaria deste Governo: o que participo a VM.ce para sua devida execução. D.G.e a VM.ce B.a 11 de Abril de 1811. Conde dos Arcos. Sr. Manoel Antonio da Silva Serva?.
\end{abstract}

A Tipografia de Manoel Antonio da Silva Serva começaria a funcionar efetivamente a 13 de maio de 1811, quando foram impressos os três primeiros folhetos, o Prospecto da Gazeta da Bahia, o Plano para o Estabelecimento de huma Bibliotheca e a Oração Gratulatoria ao Principe Regente Nosso Senhor, do padre Ignacio José de Macedo. A 14 de maio começou a circular a Idade d'Ouro do Brazil. Naquela mesma semana o Conde dos Arcos emitiu um aviso para Serva, dispondo o seguinte:

\title{
P.a Manoel Antonio da S.a Serva
}

Fique VM.ce na intelligencia, que se deve, no reverso da primeira folha do Frontespicio do Livro, imprimir sempre em todos os Exemplares, o ultimo despacho da Permissa concedida por este governo para a Imprensa, da maneira seguinte = Pode Imprimir-se. B.a = de maio de 1811, estava a Rubrica de Sua Excellencia.

Carta do Conde dos Arcos para Manoel Antonio da Silva Serva. Bahia, 11-IV-1811. APEB. Colonial/Provincial. Cartas do Governo para diversas autoridades, m. 166 (1809-1811), f. 307. 
Quanto porem a Editaes, Avizos, Gazetas, e outros papeis de huma so folha, bastara a declaração seguinte $=$ Com as Licenças necessarias. Ds. G.e A Vm.ce B.a 9 de maio de $1811=$ Conde dos Arcos $=$ Sr. Manoel Antonio da Silva Serva ${ }^{10}$.

De acordo com a carta supra, foi determinado o modo como a censura deveria ser impresa nos livros da Serva. Diferente do modelo usual em Portugal e no Rio de Janeiro, os primeiros impressos da Bahia traziam no verso do frontispício o "Pode imprimir-se", conforme a imagem abaixo. Esses primeiros folhetos não foram encaminhados para Comissão de Censura, sendo impressos com licença do Governador D. Marcos de Noronha. Diferente da forma usual em Portugal e no Rio de Janeiro, na Bahia a licença começou a ser discretamente impressa no verso da folha de rosto, conforme registrado no folheto abaixo indicado:
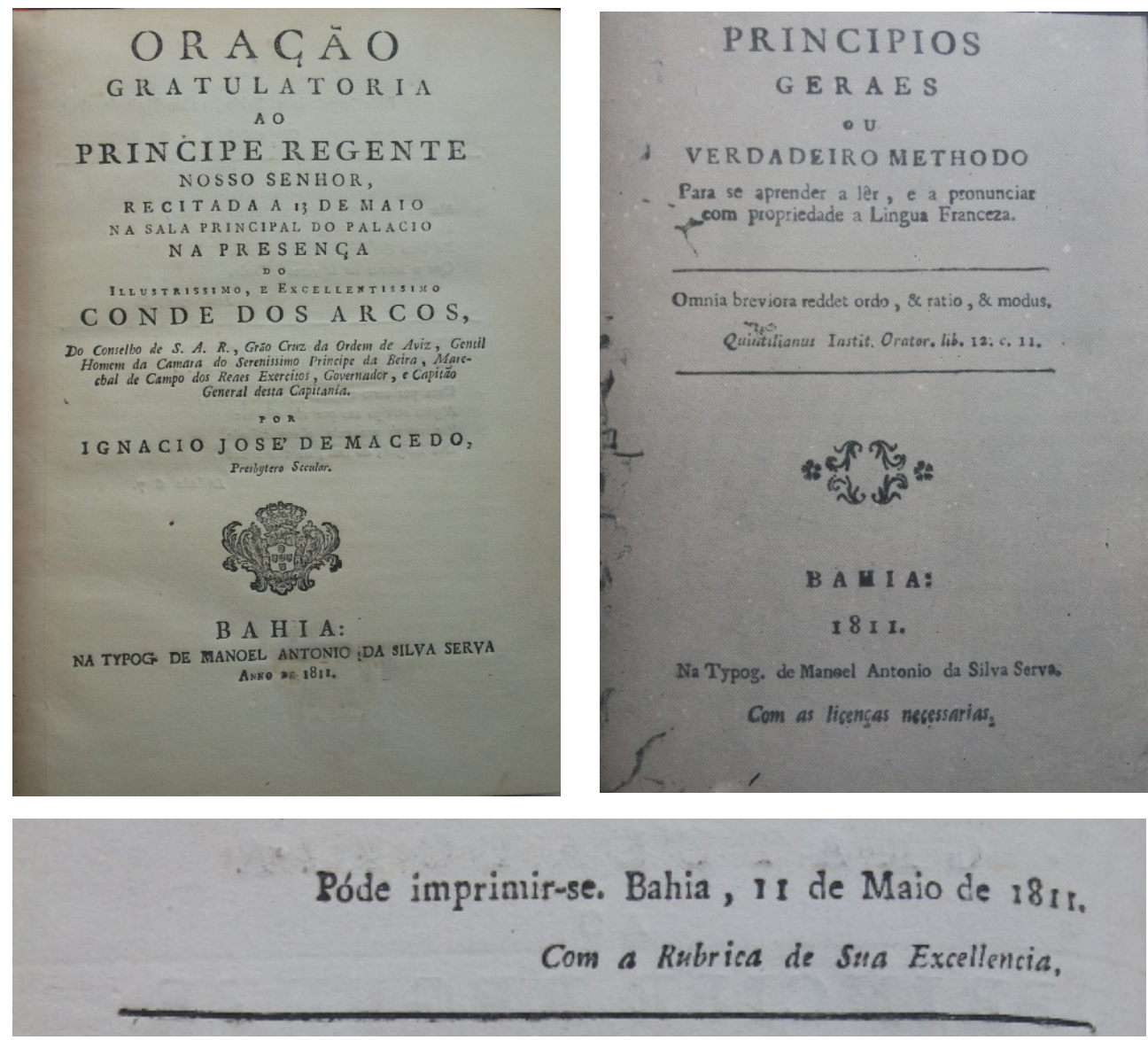

Figura. 1. Macedo, Ignacio José de. Oração Gratulatoria ao Principe Regente.

Bahia, $1811^{11}$.

10 Carta do Conde dos Arcos para Manoel Antonio da Silva Serva. Bahia, 9-V-1811. APEB. Colonial/Provincial. Cartas do Governo para diversas autoridades, m. 166 (1809-1811), f. 323.

11 Coleção do autor. 
Esse modelo de declaração da permissão foi logo substituído pelo explícito "Com as licenças necessárias", estampado ao pé do fronstispício, como era usual em Portugal e no Rio de Janeiro.

Somente a 22 de maio foi registrado o primeiro envio, pelo Conde dos Arcos, de um manuscrito para exame pelos membros da comissão de censura. As minutas da censura de livros permitem verificar uma fórmula de registro que contém os elementos fundamentais para o preenchimento desses documentos oficiais, observado pelos copiadores do Conde dos Arcos e do Conde da Palma. A fórmula obedece a seguinte sequência: 1o Destinatário, 2o Conteúdo com o título do manuscrito a ser examinado, 3o Saudação, 4o Local e data, 5o Remetente e, por fim, 6o Destinatário. Não foi possível encontrar nenhum dos pareceres dos censores. Também não foi possível localizar os registros de manuscritos remetidos para os dois censores eclesiásticos. Antes de examinar a cartas, é necessário apresentar os membros da Comissão de Censura da Bahia.

\section{Os censores bahienses}

Estabelecido os mecanismos de censura, restava ao governo indicar os censores para examinar e emitir os pareceres sobre os manuscritos antes de seguirem para a Tipografia de Serva. Coube ao Conde dos Arcos os nomearem. Os dois primeiros indicados foram o professor José Francisco Cardoso de Moraes e o coronel Pedro Gomes Ferrão Castelbranco:
P.a José Francisco Cardozo
Tendo-me Sua Alteza Real feito Mercê de anuir a minha Repreentação, e Supplica, Permittindo em Carta Regia de 5 de Fevereiro, a esta Capital, o uzo da Typogra- phia; e Ordenando o Mesmo Augusto S.r, que eu escolha para Censores das Obras, que devem imprimir-se, Pessoas de cuja probid.e, e Litteratura, eu tenha a mais perfeita confiança; e concorrendo finalm.te taes circunstancias na Pessoa de VM. ce, em observancia daquella Regia Ordem, nomeio a VM.ce Censor dos Escritos, que devem dar-se ao Prelo, na Typographia desta Capital. D.s G.e a VM.ce B.a 23 de Abril de 1811. Conde dos Arcos. Sr. José Francisco Cardozo.
Do mesmo theor, e data se expedio outra ao Coronel Pedro Gomes Ferrão Caste- lbranco $^{12}$.

O Conde dos Arcos nomeou José Francisco Cardoso de Moraes como censor e revisor da Idade d'Ouro do Brazil a 15 de janeiro de 1812.

\section{Pa José Francisco Cardozo}

Sendo necessario, em virtude da Ordem Regia, que me foi expedida pela Secretaria de Estado dos Negocios Estranjeiros, e da Guerra, encarregar a Revizão, da Gazeta desta Cid.e á pessoa que tenhas as qualidade.es precisas em materia de tanta delicadeza, e Circunspecção: nomeei a VM.ce Revizor da Gazeta Idade d'Ouro,a

12 Carta do Conde dos Arcos para o Professor Régio José Francisco Cardoso de Moraes. Bahia, 23-IV-1811. APEB, Colonial/Provincial, Cartas do Governo para diversas autoridades, m. (1810-1811), ff. 310v-311. 
fim de que se imprima, com a correcção indispensavel este periódico, que com os outros Escritos, que se dão ao Prelo; ficando VM.ce na Responsabilid.e inherente a sim.e Revizão. Ds. G.e a VM.ce B.a 15 de Janeiro de 1812 = Conde dos Arcos $=$ José Francisco Cardozo ${ }^{13}$.

As pesquisas no Arquivo Público do Estado da Bahia indicam a existência de apenas quatro censores: José Francisco Cardoso de Moraes, Pedro Gomes Ferrão Castelbranco, Francisco Carneiro de Campos e João Rodrigues de Brito. O Almanach para a cidade da Bahia anno 1812, impresso também pela Serva, cujo único exemplar conhecido encontra-se na Academia de Ciências de Lisboa, complementa a lista dos censores que atuavam na Bahia, indicando mais três indivíduos. Segue abaixo o registro:

Que na conformidade do disposto na Carta Regia de 5 de Fevereiro de 1811, escripta ao Excellentissimo Sr. Governador, e Capitão General, estão deputados para a Revisão e censura dos livros, e papeis que se queirão offercer ao prélo.

Por parte do Governo

O Conselheiro Antonio Luiz Pereira da Cunha

O Desembargador João Rodrigues de Brito

O Coronel Pedro Gomes Ferrão

José Francisco Cardoso

Por parte do Prelado Metropolitano

O Conego José Fernandes da Silva Freire

O Padre Mestre João Machado, da Congregação do Oratorio ${ }^{14}$.

Dos sete censores bahienses identificados, o mais ativo foi o professor José Francisco Cardoso de Moraes, para quem foi remetido 23 manuscritos de um total de 44 identificados, ou seja, 52,27\% da censura de livros para impressão na capitania da Bahia coube a ele. Foi seguido por Francisco Carneiro de Campos, responsável pela censura de 16 manuscritos, que perfaz 36,36\% do conjunto. Por fim, há Pedro Gomes Ferrão Castebranco, que atuou na Comissão de Censura entre 1811 e 1814, examinando apenas quatro manuscritos, num total de 9,09\%. A curta atuação deste é explicada pelo seu falecimento naquele ano. Foi possível identificar apenas um manuscrito examinado pelo desembargador João Rodrigues de Brito, então com. $2,27 \%$ do montante da censura. Não foi possível localizar nenhuma indicação de manuscritos censurados por Antonio Luiz Pereira da Cunha.

Quem foram esses censores? O primeiro e mais atuante, o professor de latim José Francisco Cardoso, é um ilustre desconhecido nas letras e na história do Brasil. Nasceu em Cachoeira, filho do vigário da Igreja de Nossa Senhora do Rosário, Gonçalo Cardoso de Moraes, e de dona Ana Josefa do Espírito Santo, mulher branca e solteira. Foi reconhecido pelo pai por meio de uma Escritura de filiação e legitimação datada de 4 de junho de 1800. Passou a ser chamado por José Francisco Cardoso de Moraes. As relações intelectuais que ele estabeleceu na Corte entre 1800 e 1802, e até mesmo antes desse período, como demonstra a epístola Elmano a Josino que

13 Carta do Conde dos Arcos para o Professor Régio José Francisco Cardoso de Moraes. Bahia, 15-I-1812. APEB, Colonial/Provincial, Cartas do Governo para diversas autoridades, m. (1811-1814), ff. 60v-61.

14 Almanach, 1811: 234-235. 
Manuel Maria Barbosa du Bocage lhe escreveu da Índia em 1787, é em muitos aspectos obscura, mas essencial para entender suas afinidades políticas ${ }^{15}$. Na referida epistola Bocage lhe narrou como se descobriu a Conjuração dos Pintos a 5 de agosto de 1787, em que a guarnição militar portugueza esteve em risco de ser exterminada. A primeira vez que Bocage reconheceu publicamente a identidade de Josino como José Francisco Cardoso fora na tradução do poema As Plantas, no verso "Revive em ti Josino, a Lacia Musa", para, em seguida, identificá-lo como o "Author do Canto heroico á Expedição de Trípoli"16. A obra de Cardoso é tão ampla (e obscura) que merece um estudo à parte.

Em fins de 1800 José Francisco Cardoso seguiu para Portugal. Justificou a viagem por questões de saúde e particulares, mas é certo que a mesma teve fins políticos no que tange a sua ascenção em cargos públicos ${ }^{17}$. Deixou o jovem Manuel Matias Vieira Fialho de Mendonça (o Crinauro), em Salvador, como substituto na cadeira de Gramática Latina. Era uma condição para realizar a viagem. Em Lisboa, aproximouse fr. José Mariano da Conceição Veloso e de Simão Thaddeo Ferreira, o impressor que por esse tempo havia alcançado a nomeação de administrador geral da Typographia Regia, novamente organizada por decreto de 7 de Dezembro de 1801, sob os auspícios de D. Rodrigo de Sousa Coutinho, que pouco antes passara do ministério dos Negócios Ultramarinos para o da Fazenda. Em Lisboa alcançou mercê para todas as suas súplicas, dentre as quais a jubilação do cargo de professor régio com ordenado integral e um novo cargo de escrivão da Chancelaria da Bahia ${ }^{18}$. Retornou para o Brasil em meados de 1802, como pode-se inferir pelo documento abaixo:

Manda o Principe Regente Nosso Senhor, que se não ponha impedimento algum a passar para a Bahia José Francisco Cardozo Professor Regio de Gramatica Latina naquella cidade, por constar que veio dali com a devida Licença, e que agora se recolhe. Mafra em 11 de novembro de 1801.

Visconde de Anadia ${ }^{19}$.

Outro censor foi Pedro Gomes Ferrão Castelbranco, sem dúvida um dos maiores conhecedores de livros na Capitania da Bahia. A Biblioteca Pública da Bahia foi criada por diligência sua, junto com Francisco Agostinho Gomes. Pedro Gomes foi o autor do Cathalogo dos Livros que se Achão na Bibliotheca Pública da Cidade da Bahia, que se acreditava, até recentemente, ter sido impresso em 1818 em vista do único exemplar conhecido na Biblioteca Nacional do Rio de Janeiro estar falto da folha de rosto, arrolando 737 títulos. Borba Moraes levantou uma questão: "Em que data terá sido impresso o catálogo?" ${ }^{20}$. Hoje é possível responder essa pergunta. Não encontramos um exemplar mais completo do Catálogo, com a folha de rosto, mas uma carta autógrafa de Pedro Gomes Ferrão Castelo Branco para o conde da Barca,

15 Bocage, 1799: 182-188.

16 Bocage, 1801: X-XI.

17 Requerimento do professor de Gramática Latina José Francisco Cardoso ao governador-geral solicitando licença para ir a Lisboa. Queluz, 4-II-1800. Arquivo Histórico Ultramarino de Lisboa [Portugal] (em diante AHU), Bahia, Cx. 208, D.14794.

18 Requerimento do professor de Gramática Latina da Bahia, José Francisco Cardoso, ao príncipe regente solicitando jubilação com ordenado integral. Lisboa, 8-IX-1800. AHU, Bahia, Cx. 218, D. 15254.

19 Passaporte de José Francisco Cardoso de Moraes. Mafra, 11-XI-1801. AHU. Livro de Passaportes de Passageiros, $\mathrm{n}^{\circ} 8$ (1798-1806), f. 158.

20 Moraes, 1979: 151. 
datada em 7 de setembro de 1813:

Ill.mo e Ex.mo Senhor

Quando tive a honra de receber a de VEx.cia em data de 2 de janeiro deste anno, achava-me fora da cidade onde não podia responder a VEx.cia como devia, o que me apresso a fazer agora dando a VEx.cia os mais sinceros agradecimentos pela generosa subscripção, que mandou fazer a Livraria Publica desta Cid.de, tanto mais precioza por ser VEx.cia conhecido, e respeitado, no Mundo Político, e Litterario, ainda mais p.las suas luzes, que p.los seus elevados empregos. Não me avistei ainda com o meo Am[ig].o Domingos Borges [de Barros], p.r ter elle andado tãobem, pr fora da Cid.e, porem penso que brevem.te se ha de recolher à ella, e depois que falarmos hei de tornar a tomar a liberdade d'escrever a VEx.cia. Remetto a VEx.cia o Plano primeiro desta Livraria, o pequeno Discurso d'Abertura della, e o Cathalogo, que temos impresso dos Livros, que contem, e mandarei o Suplemento, q' se vai imprimir agora, e ha de ser quase igual em volume ao Cathalogo.

Agradeço muito à VEx.cia as expressoens com que me ezalta [sic] bem que as não mereça, pelo que respeito a Fundação deste Estabelecimento, se não pela peq.a parte, que tive em Coadjuvar as vistas do Ex.mo Senhor Conde dos Arcos.

Bahia 7 de Setembro de 1813 De V. Ex.cia Ill.mo e Ex.mo Senhor Antonio de Araujo e Azevedo. Pedro Gomes Ferrão Castelbr.co ${ }^{21}$.

O Catálogo é mais antigo do que se supunha, já tendo sido impresso em 1813. A carta revelou, não obstante, que existia um Suplemento que estava em vias de ser impresso, naquela data. Essa impressão teria se realizado? Somente o aprofundamento das pesquisas poderá responder isso. Pedro Gomes faleceu no ano seguinte e a direção da Biblioteca da Bahia para seu primo, o bibliófilo Francisco Agostinho Gomes.

O censor João Rodrigues de Brito é conhecido por ser o autor das Cartas economico-politicas sobre a agricultura: e commercio da Bahia, escritas em 1807, mas publicadas em Lisboa somente em 1821. Bacharel formado em Direito pela Universidade de Coimbra, após servir na Bahia, Rodrigues de Brito foi nomeado a 13 de outubro de 1820 desembargador da Casa da Suplicação em Lisboa ${ }^{22}$. Foi Deputado às Cortes constituintes em 1821. Natural de Évora, era o único membro da Comissão de Censura da Bahia nascido no Reino. Era irmão do magistrado Joaquim José Rodrigues de Brito, que travou um debate com o liberal bahiense José da Silva Lisboa, autor das Observações sobre a prosperidade do estado pelos liberaes principios da nova legislação do Brazil, que foi submetido pelo Conde dos Arcos à censura de João Rodrigues de Brito (Carta no 2, no Anexo). O censor publicaria em 1821, na capital portuguesa, um opúsculo intitulado $O$ Dedo do Gigante Apontando ao Alvo da Publica Prosperidade a Liberdade do Commercio, que posteriormente o autor tomou a deliberação de suprimir. Sua visão acerca do papel político da imprensa é reveladora da sua orientação liberal:

21 Carta de Pedro Gomes Ferrão Castelbranco para o Conde da Barca. Bahia, 7-IX-1813. Universidade do Minho-Arquivo Distrital de Braga [Portugal], Fundo FAM/FAA Família Araújo de Azevedo 1489/1879, Cota Atual B-7(11, 2), 4 pp.

22 Carta. Desembargador Graduado em Agravos da Casa da Suplicação de Lisboa. Lisboa, 13-X-1820. Arquivo Nacional da Torre do Tombo, Lisboa [Portugal] (en adelante ANTT), Registo Geral de Mercês, D. João VI, lib. 16, f. 36 . 
Pelo que respeita ás causas provenientes da falta d'instrucção, o remedio he dissipar as trevas da ignorancia, ordenando que todas as pessoas de ambos os Sexos saibão ler, escrever, e contar; estabelecendo as instituições, cuja falta a cima lastimei, e hum bom systema de estudos, como tambem fica indicado, honrando, e favorecendo os que se distinguirem, principalmente na Sciencia economica, que, sendo a mais Importante, he a mais ignorada. Devião criar-se Cadeiras para ella em todas as partes, onde houvesse suficiente numero de alumnos para frequenta-las; sem este preparatorio ninguem devera matricular-se na Universidade, nem ser admittido a servir empregos publicos de qualquer natureza que fossem. Mas todas estas benéficas instituições, e outras semelhantes, de pouco aproveitarão, para espalhar os conhecimentos humanos sem a liberdade de pensar, e publicar os pensamentos por todos os meios conhecidos, principalmente o da imprensa. Esta preciosa liberdade habilita o Filosofo a instruir a hum tempo o genero humano todo nos mais reconditos lugares do Globo. Espalhando as luzes, como o Sol, descobre todas as manchas, e põe á vergonha os velhacos, e os empregados publicos prevaricadores, que por isso tremem della, pintando-a sempre com feias côres, como perturbadora do socego publico, e com razão; porque ella põe os espiritos em movimento, rasga as cortinas, e mascaras dos cortezãos, e as vendas que tapão os olhos aos Monarchas, deixando penetraria luz da verdade onde sem aquella liberdade ella jamais entrou. O povo, que lograr esta ventura, não póde retrogradar; porque a mesma diffusão das luzes descobre os perigos apenas apparecem, e ao mesmo tempo os remedios ${ }^{23}$.

Outro censor, segundo o Almanaque de 1812, foi Antônio Luís Pereira da Cunha, posteriormente visconde e marquês de Inhambupe. Não há, contudo, registros de que ele examinou manuscritos submetidos para a impressão. Pereira da Cunha nasceu em Salvador a 6 de abril de 1760, filho de Bartolomeu Pereira da Silva e Ana da Cunha Barbosa, e na sua cidade cursou os estudos básicos de matemática e filosofia. Seguiu para o Reino onde se matriculou na Universidade de Coimbra em 20 de dezembro de 1782. Formou-se em Direito em 4 de maio de 1787, entrando para a magistratura no cargo de juiz de fora em Torres Vedras (1789). Regressou ao Brasil, foi ouvidor na Bahia e desembargador em Pernambuco (1792), compondo o governo interino daquela capitania (1798). Atuou em Minas Gerais entre 1802 e 1806, quando retornou para Salvador, nomeado Chanceler da Relação da Bahia e, naquele ano ainda, alçado ao Conselho da Fazenda. Em 1809, fez parte do governo interino da Bahia, indicado em 1811 como membro da Comissão de Censura. Em 1818, foi deputado da junta de comércio, agricultura, fábricas e navegação e no ano seguinte nomeado fiscal das mercês, exercendo em 1821 o cargo de intendente geral de polícia. Foi ministro da Fazenda, do Império e dos Estrangeiros, constituinte (1823) e eleito por Pernambuco para o Senado do Império do Brasil, de 1826 a 1837, instituição que presidia quando faleceu no Rio de Janeiro, em 19 de setembro de 1837.

Após a morte de Castelbranco, o Conde dos Arcos nomeou o professor de filosofia Francisco Carneiro de Campos para compor a Comissão de Censura. Campos nasceu em na Bahia em 1779 na Bahia. Formado em Direito pela Universidade de Coimbra, ocupou o cargo de professor de filosofia em Salvador, desde $1797^{24}$. Casa-

Brito, 1821: 66-67.

24 Nomeação de Francisco Carneiro de Campos para a Cadeira de Filosofia da Cidade da Baía. Lisboa, 25-IV- 
do na Freguesia de Santana, em 21 de setembro de 1809, com Maria José Carolina Maya, foi nomeado Juiz de Fora dos Orfãos de Salvador a 29 de março de 1819, acumulando-o com a função de censor ${ }^{25}$. Possivelmente por conta de suas relações nos quadros da maçonaria, ascendeu politicamente tonando-se Desembargador da Relação da Bahia e da Casa da Suplicação. Em 1822 fez parte da Junta Provisória da Bahia. No Rio de Janeiro foi eleito Deputado Constituinte pela Bahia e na Corte foi nomeado Ministro dos Negócios Estrangeiros e, por fim, do Supremo Tribunal de Justiça. Faleceu no Rio de Janeiro a 8 de dezembro de 1842.

Havia dois eclesiásticos na Comissão de Censura. O mais influente foi José Fernandes da Silva Freire, nomeado Censor Eclesiástico pelo Arcebispo por portaria de 24 de maio de $1811^{26}$. Natural da Freguesia de Nossa Senhora da Conceição da Praia, em Salvador, nasceu a 23 de agosto de 1777, sendo batizado a 23 de outubro do mesmo ano. Foi seminarista no Rio de Janeiro, onde recebeu ordens menores e o subdiaconato. Seguiu para a Universidade de Coimbra e se tonou bacharel em Teologia a 8 de junho de 1805 . Foi ordenado presbítero aos 30 anos, em 21 de dezembro de 1807, por D. Frei José de Santa Escolástica, na cidade onde nasceu. Na Sé da Bahia ocupou o cargo de Cônego prebendado por carta do Príncipe Regente de 22 de julho de 1807, antes mesmo de haver sido ordenado padre. Foi nomeado Provisor Sinodal a 26 de julho de 1808 e Provisor e Juiz das jutificações De Genere a 10 de dezembro de 1814.

Em maio de 1817, o Deão da Sé, Antonio Borges Leal, ordenou aos párocos de todas as freguesias que exortassem seus paroquianos para se mater fiéis ao monarca português contra a Revolução Pernambucana de $1817^{27}$. O Cônego da Sé, José Fernandes de Silva Freire, cumpriu a ordem do Deão, publicando sua exortação na Idade d'Ouro do Brazil, a 27 de maio de 1817. Com a morte (ou assassinato) do Arcebispo Fr. Dâmazo em 1816 e, posteriormente, de Borges Leal em 1820, Silva Freire tornou-se a maior autoridade religiosa na Bahia. Elevado a Arcediago por Carta Régia de 17 de setembro de 1817, foi alçado a Tesoureiro-mór e Deão por Carta Régia em 1820. Publicara em 1821 uma Pastoral, "escrita com a precisão, e clareza que caracterizam os escritos deste Sábio Cidadão, e aonde os nobres sentimentos patrióticos de que ele está possuído, inspiram o mais cordial patriotismo", mas da qual não foi possível encontrar exemplar ${ }^{28}$.

O sétimo censor a atuar na Bahia foi o Padre Mestre João Machado, superior da Congregação do Oratório em Salvador, instalada naquela cidade desde 1755, no Hospício de São Felipe Neri. Pouco foi possível apurar acerca dele, mas nasceu no Recife, onde fez os seus estudos, recebeu ordens sacras e foi escolhido para reger a cadeira régia de latim. Lino do Monte Carmello Luna o descreveu como "sacerdote de conhecimentos, e erudição, ele a desenvolvia louvavelmente nas cadeiras de Filosofia, e Teologia, cujas disciplinas ensinava na sua Congregação [...] gozando o bom nome de excelente pregador e profundo teólogo" 29 . E notável que dos sete censores, seis eram brasílicos, sendo cinco bahienses e um pernambucano. Apenas

1797. ANTT, Registo Geral de Mercês de D. Maria I, liv. 28, f. 285v.

25 Carta de nomeação de Francisco Carneiro de Campos para o cargo de Juiz de Fora dos Órfãos. Bahia, 29-III-

1819. APEB, Colonial/Provincial, Cartas do Governo para diversas autoridades, m. 172-1 (1819-1821), f. 3.

26 Costa e Silva, 2000: 410-411.

$27 \quad$ Idade d'Ouro do Brazil, $\mathrm{n}^{\circ}$ 34, 2-V-1817.

28 Semanário Cívico, $\mathrm{n}^{\mathrm{o}}$ 17, 21-VI-1821.

29 Luna, 1857: 93. 
João Rodrigues de Brito era nascido em Portugal. A predominância de um grupo majoritariamente brasílico na Comissão de Censura é um fator demasiado importante, visto que à época os ânimos patrióticos e as tensões separatistas aumentaram significativamente.

A Comissão de Censura na Bahia era peculiar também em outros aspectos políticos. Um elemento comum à maior parte dos seus membros foi a iniciação na maçonaria, sociedade secreta vista com desconfiança pelas autoridades portuguesas e que em 1818 foi posta na ilegalidade. Em 1817, o censor José Francisco Cardoso foi acusado, em duas denúncias, de introduzir a maçonaria na Bahia por volta de 1800 . A mais contundente das acusações foi apresentada por certo frei Amador da Sancta Cruz (que penso que ser um pseudônimo), numa carta destinada a D. João VI, que revela a ligação do censor com os pedreiros livres na Bahia. A carta denunciou ao monarca que $[\ldots]$

a malvada seita dos Pedreiros Livres, cujo principal acento he nesta Cidade, plantada, há mais de vinte annos por Joze Francisco Cardozo[...]. Os Padres Ignacios, Gazeteiro, o M.e de Grammatica, e outro mestre da mesma lingoa, Dominicano, e o Substituto das mesmas Cadeiras são iguaes aos antecedentes, todos elles profanadores do seo estado, e as mais fortes columnas da Massonaria; elles são, q. explicão o cathecismo, e Ritual das funçoes massonicas, cujo livro foi impresso em Londres com o titulo $=$ Compendio p.a o Oriente da Bahia= na Impressão de Segredo $^{30}$.

O conteúdo da carta era grave visto que em 1817 a maçonaria foi responsável pela turbulência política nos dois lados do Atlântico. Em Portugal ocorreu a Conspiração de Gomes Freire de Andrade, levando ao cadafalso doze pessoas acusadas de Inconfidência, incluindo o próprio líder, que ocupava naquele ano o cargo de GrãoMestre do Grande Oriente Lusitano. Na América portuguesa teve início, em março, a Revolução Pernambucana, chefiada por Domingos José Martins. Isso colocou o governo português em alerta contra a maçonaria e as sociedades secretas, apesar de muitos membros do governo em Portugal e no Brasil serem inciados em lojas maçônicas. O fato é que o governo outorgou a lei que proibia o funcionamento de todas as sociedades secretas no Império português. Decerto que isso não as impediu de continuar atuando clandestinamente.

Também não se trata de uma denúncia vazia. Os nomes de figuras importantes foram revelados, bem como o livro utilizado nos rituais daquela sociedade iniciática. Apesar da denúncia, não há registro de que os nomes ali implicados fossem investigados pelo governo. Além disso, o documento indica que havia uma ligação muito mais profunda entre os censores e o grupo que atuava na Tipografia de Serva. José Francisco Cardoso ao lado do jornalista Ignacio José de Macedo explicava o Catecismo da maçonaria ${ }^{31}$.

José Fernandes da Silva Freire também integrava a cabala maçônica da Bahia, ao lado de José Francisco Cardoso e Ignácio José de Macedo (1774-1834). Nomeado Inspetor no recém-criado Seminário de São Dâmazo, por portaria de 15 de agosto de 1815, foi acusado, de acordo com fr. Sancta Cruz, de colocar naquela instituição

Pereira, 1956: 251-252.

31 Magalhães, 2013: 221-262. 
um confrade maçom, identificado como o franciscano fr. Luiz de Santa Teresa. Mais grave, decerto, é a acusação abaixo transcrita:

o Provizor do Arcebispado he hum dos mais execrandos Pedreiros-Livres; sendo Conego não frequenta nunca o Coro, não reza, nem diz Missa, e quando por obrigação a deve dizer na Sé pede, ou paga a quem as diga. O Verão passado athe á procição [sic] dos Passos conservou-se na sua quinta na Barra fazendo n'ella continuados jantares massonicos, e conventiculos, sendo ferquentes [sic] socios d'ellas o Marechal [Madeira de] Mello, homem de caracter detestavel pela falta de Religião, e de moral. Este Padre com os seos estratagemas innsinuou-se no animo do defuncto Arcebispo, e de maneira tal, q com as suas intrigas, e cabalas sacrificou á morte o innocente Prelado, muito mais quando soube, q elle reprezentava a V. Mag.e contra os Pedreiros-livres ${ }^{32}$.

A partir de 10 de fevereiro de 1821, Freire integrou a Junta Provisória do Governo, comprometendo-se com a causa Portuguesa. Teve que deixar a Bahia após a derrota dos lusos na Guerra de Independência, acompanhando Madeira de Melo e Ignacio José de Macedo no retorno para o Reino. Christiano Muller, no começo do século XX, encontrou a carta demissória de Silva Freire, com data de 2 de julho de 1823, pela qual o Deão alegava perante o Cabido "ser causa desta demissão o querer pôr em segurança a sua pessoa e a sua vida ex-vi das tristes circunstâncias em que se achava esta Província da Bahia, as quais obrigavam a retirar-se para Lisboa"33. Silva Freire morreu na capital portuguesa em 1830.

José Francisco Cardoso e José Fernandes da Silva Freire não foram os únicos membros da Comissão de Censura acusados de pertencerem a franco-maçonaria. Antônio Luiz Pereira da Cunha também foi implicado na denúncia de jurar bandeiras francesas em 1817, após a Revolução Pernambucana. Pedro Gomes Ferrão já estava morto quando as denúncias vieram à tona em 1817, mas Alexandre Gomes Ferrão, seu parente, foi implicado também, bem como o bibliotecário Lúcio José de Matos, com quem ele trabalhava ${ }^{34}$. Seu primo Francisco Agostinho Gomes é cotumaz suspeito de ser pedreiro-livre desde 1798, mas o nome deste não foi incluído em nenhuma das duas denúncias de 1817 . Não foi encontrado, contudo, nenhum documento que associe João Rodrigues de Brito e o oratoniano João Machado à maçonaria.

A Comissão de Censura na Bahia pode ser definida com a imagem da raposa guardando o galinheiro. Os censores eram certamente homens de espírito liberal, em sua maioria ligados pela fraternal associação da maçonaria, posta na ilegalidade me 1818. Revelar as particularidades biográficas dos censores é necessário para compreender a natureza dos livros que estavam sendo liberados para publicação na Tipografia de Manoel Antonio da Silva Serva.

Pereira, 1956: 251-252.

Muller, 1923: 5-10.

Biblioteca Nacional do Rio de Janeiro, 1953: 204-206. 


\section{As obras censuradas}

Nesse estudo sobre a censura na Bahia o protagonismo deve caber ao objeto censurado: o livro. A partir das cartas enviadas pelo governo aos membros da Comissão de Censura é possível observar os registros das obras manuscritas que seguiam para a Tipografia de Serva, para tentar compreender a conjuntura intelectual e a produção de impressos entre 1811 e 1821.

Dos 44 manuscritos submetidos à membros da Comissão de Censura, não foi possível encontrar nenhum exemplar impresso de 28 deles, ou seja, $63,6 \%$ do total. Alguns poucos podem não ter sido aprovados para publicação, mas a maioria dos impressos desapareceu sem ter restado um único exemplar. Por isso, para identificar com mais acuidade o que estava sendo impresso na Bahia, é necessário o exame do conteúdo de cada uma das cartas emitidas para a Comissão de Censura, trancritas no anexo deste artigo.

A primeira obra a ser submetida ao crivo dos censores foi o manuscrito dos Principios Geraes ou Verdadeiro Methodo Para se aprender a lêr, e a pronunciar com propriedade a Lingua Franceza, folheto anônimo com 22 páginas (Carta no 1 no anexo). Apesar do anonimato, é notório que seu autor foi Diogo Soares da Silva e Bivar, então acusado de inconfidência em Portugal e preso desde 1810 no Forte de São Pedro, em Salvador ${ }^{35}$. Bivar (6 de fevereiro de 1785 - Rio de Janeiro, 10 de outubro de 1865) foi um dos mais atuantes intelectuais nos primeiros tempos da imprensa bahiense, colaborando com o padre Ignacio José de Macedo na redação de a Idade d'Ouro do Brazil. Além disso, Bivar tomou parte na redação da revista As Variedades, considerada a primeira do Brasil, publicada em 1812. Foi também o autor do Almanaque da Bahia para 1812, impresso em fins de 1811, o primeiro do gênero que se imprimiu no Brasil. Bivar ousou, numa época em que francesia e jacobinismo eram sinônimos na Bahia, publicar em Salvador seu pequeno compêndio gramatical francês, tão bem recebido que o livreiro francês Rolland, radicado em Lisboa, imprimiu a segunda edição na capital portuguesa em 1820, com 32 páginas, também anonimamente. Diogo Soares da Silva e Bivar era pedreiro-livre, segundo afirma o mais competente estudo sobre a maçonaria portuguesa, o que pode explicar a proteção que lhe deveu o Conde dos $\operatorname{Arcos}^{36}$. A influência de Bivar é demasiado atípica, nos quadros da política portuguesa da época. Miguel Calmon du Pin e Almeida revelou que o próprio Conde dos Arcos remeteu ao inconfidente papéis de natureza econômica enquanto ele esteve preso em Salvador, o que lhe permitiu escrever o $\mathrm{Al}$ manaque para 1812. Bivar só foi isentado do crime de inconfidência por decreto de D. João VI de 26 de março de 1821, quando foi restituído à sua liberdade com todos os seus direitos, honras e prerrogativas.

O inocente Pricipios Geraes não foi o único texto de Bivar a ser submetido à Comissão de Censura. Reputo pertencer a ele a tradução bahiense de Atalá, ou os amores de dous selvagens no deserto, por Chateubriand: traduzido em linguagem Portugueza por ***, que foi submetido à censura em 1817 e impresso em 1819 (Car-

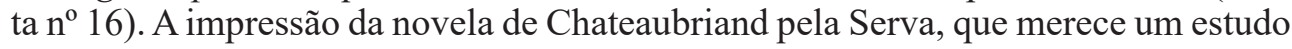
à parte, comprova a autonomia e a falta de comunicação entre a Comissão de Censu-

Requerimento de Diogo Soares da Silva Bívar, que fora preso no forte de São Pedro, na Bahia. Bahia, 1816. AHU, Bahia, Cx. 259, D. 18072.

36 Oliveira, 1990: 351. 
ra da Bahia e o aparato censorial de Portugal. No caso da Atalá é surpreendente que o censor e a Tipografia aprovaram e imprimiram um livro que apenas cinco anos antes, em 1812, havia sido proibido de circular por ordem do Santo Ofício de Lisboa ${ }^{37}$.

Isso mostra que a Serva imprimiu na Bahia livros proibidos em Portugal. Ignacio José de Macedo, o mais profícuo escritor e publicista da Bahia entre 1811 e 1822, que não teve nenhum de seus impressos registrados na correspondência entre o governador e a Comissão de Censura, confirma a liberdade com que livros ne natureza liberal circulavam na capitania da Bahia. O Velho Liberal do Douro, como ele mesmo se intitulou, observou que nos anos de 1810 e 1820 "lidei no Brazil com os homens mais Liberaes, e que mesmo antes de falar em Constituição Portugueza erão homens amigos de ler livros com idéas liberaes, que na Bahia corrião com mais franqueza, que em Portugal; porque ali houve sempre uma Liberdade de facto, muita propensão a livros filosóficos" "38. A já citada denúncia de fr. Amador da Santa Cruz revelou também que:

A lição dos Livros prohibidos pela Santa Madre Igreja e pelo Estado existe nesta Cidade [do Salvador] com tanta franqueza como se deve ler as sagrada Bíblia. O Bibliothecario da Livraria Pública [Lúcio José de Matos] os dá a ler a qualquer moço, que apenas saberá os artigos da Fé e por isso os moços tractão de resto os mais sagrados Dogmas da Religião e por esta forma vão crescendo em todo o genero de impiedade ${ }^{39}$.

A impressão de livros proibidos na Bahia é ainda mais grave na medida em que, conforme recentemente demonstrado, os livros ali impressos não eram vendidos apenas naquela Capitania, mas comercializados em Portugal, continuamente entre 1811 e 1821, pelos principais livreiros de Lisboa, Porto, Coimbra e Lamego, por meio de uma rede estabelecida por Manoel Antonio da Silva Serva e, possivelmente, por seu familiar Manoel José da Silva Serva, rico maçom que servia de tesoureiro no Grande Oriente Lusitano, possuidor de uma livraria no Rossio ${ }^{40}$. A Tipografia de Serva publicou em 1815, inclusive, a Paráfraze dos Provérbios de Salomão, obra de cunho maçônico dissimulada em versos bíblicos, onde mais de uma vez a palavra Deus é substituida por Arquiteto do Universo. Esse poema, de José Eloi Ottoni, foi amplamente difundido no Brasil e em Portugal ${ }^{41}$.

Apesar dessa liberalidade em circular livros clandestinos ou imprimir os que haviam sido proibidos no Reino, observada tanto por Macedo quanto por Sancta Cruz, personagens em campos políticos opostos, em maio de 1819 o secretário de Estado do Brasil, Francisco Elesbão Pires de Carvalho e Albuquerque, reforçou junto à tipografia de Manoel Antonio da Silva Serva as instruções para a censura de avisos na Idade d'Ouro do Brazil:

P.a o Proprietario da Typographia M.el Antonio da S.a Serva

O Ill.mo, e Ex.mo Senhor Conde da Palma Gov.or, e Cap.am General desta Capita-

\footnotetext{
37 Censura da Átala por João Baptista Rodrigues Leitão. Lisboa, 30-X-1812. ANTT, fundo Real Mesa Censória, cota: cx. no 71, m. 74 .

38 Macedo, 1833: 315-317.

39 Pereira, 1956: 251-252.

40 Magalhães, 2014: 438-440.

41 Magalhães, 2015.
} 
nia ordena a VM.ce, q' d'ora em diante se não publique na Gazeta avizo algum de qualquer natureza, q' seja sem previa ordem do m.mo Ex.mo Snr, enviando VM.ce p.a este fim a esta Secretaria até o meio dia do dia anteced.e, em q ha de sahir a Gazeta os ditos avizos p.a obterem Permissão de S. Ex.a, a fim de poderem ser publicados entendendo-se q se irão com a Rubrica de S. Ex.a ou com Officio meu a VM.ce, ou a quem suas vezes fizer, o q autorizando a sua publicação partecipo a VM.ce. B.a 6 de Maio de 1819, Francisco Elesbão Pires de Carvalho e Albuq.e,, Snr Manoel Antonio da S.a Serva Proprietario da Typor ${ }^{42}$.

O fato é que a Comissão de Censura trabalhou initerruptamente por uma década. O primeiro manuscrito censurado por José Francisco Cardoso de Moraes, de que há registro, foi o Canto heroico, ao Natalicio do Principe Regente Nosso Senhor (Carta $n^{\circ} 3$ do Anexo), por João da Costa Carneiro de Oliveira, que até o presente nunca fora mencionado pelos estudiosos dos impressos e da literatura luso-brasileira. Nascido em Salvador a 9 de novembro de 1749, João da Costa Carneiro de Oliveira era filho do advogado Manoel da Costa Carneiro e de Soteria Maria de Oliveira. Estudou Direito e Leis na Universidade de Coimbra entre 1769 e 1776, tomando posse como Procurador do Conselho do Senado da Câmara da Bahia a 19 de janeiro de 1773 . Foi nomeado juiz de fora da Bahia por carta régia de 31 de outubro de 1798, tomando posse a 13 de fevereiro de 1799. Na mesma data tomou posse da provedoria das fazendas de defuntos e ausentes, cargo que exerceu até 27 de novembro de 1802 . Oliveira foi, inclusive, o juiz de fora que presidiu as execuções dos quatro condenados à pena capital na Conjuração Baiana ${ }^{43}$. Sacramento Blake e Borba de Moraes não registram seu nome. É possível que o Canto Heroico tenha sido impresso em 1812 e que não tenha sobrevivido sequer um exemplar.

Alguns dos manuscritos examinados pela censura, apesar de não encontramos exemplares dos livros, decerto foram impressos porque seus títulos foram anunciados para venda na Idade d'Ouro do Brazil. Esse é o caso da Filosofia Química de Fourcroy (Carta $n^{\circ} 12$ do Anexo), cuja a tradução, impressa pela primeira vez em Lisboa em 1801, foi feita pelo médico Manuel Joaquim Henriques de Paiva, mais um personagem controverso e interessado nas ideias políticas francesas, que foi levado ao Santo Ofício de Coimbra e desterrado no Brasil. Não é conhecido nenhum exemplar do Filosofia Química impresso na Tipografia de Serva, mas no ano seguinte, em 1816, a Impressão Régia do Rio de Janeiro o reeditou com uma advertência, datada da Bahia, a 25 de dezembro de 1814. A Carta no 23 refere-se também a outra tradução de Henriques de Paiva intitulada Manual de Medicina e Cirurgia Pratica Fundada Sobre o Systema de Brown pelo Dr. Belchior Adão Weikard, impressa em quatro volumes.

Além dos livros médicos acima indicados, a Tipografia de Serva publicou outros títulos de medicina, pricipalmente no seu primeiro (1811-1819) e segundo períodos (1819-1827). As Cartas $n^{\circ} 4,8,11$, e 15 (ver Anexo) também se referem a manuscritos médicos e os três primeiros são de autoria do doutor José Soares de Castro. A de $\mathrm{n}^{\mathrm{o}} 4$ trata dos Elementos de Osteologia Pratica, offerecidos ao Illustrissimo Senhor

42 Carta de Francisco Elesbão Pires de Carvalho e Albuqueque para Manoel Antonio da Silva Serva. Bahia, 6-V1819. APEB, Colonial/Provincial, m. 172-E (1819-1820), ff. 7v-8.

43 Requerimento de João da Costa Carneiro de Oliveira, filho do advogado Manuel da Costa Carneiro, no qual pede a mercê do Habito da Ordem de Christo em remuneração de seus serviços. Bahia, 1805. AHU, Bahia, Catálogo Eduardo Castro, Cx. 140, Docs. 28.088-28.124. 
Doutor José Correia Picanço (1812), que é a primeira das quatro partes do Tratado de Anatomia que Soares Castro imprimiu na Serva para uso dos seus alunos. É seguido pelas Memorias physiologicas, e praticas sobre o aneurisma, e a ligadura das arterias. Por J. P. Maunoir (1815), e pela segunda parte do Tratado de anatomia. Da myologia, parte II. Por José Soares de Castro (1813). Apenas desse último não foi possível localizar exemplar, que foi descrito J. A. Pires de Lima como "Tratado de Anatomia. Da Myologia, parte II. Bahia. Anno MDCCCXIII. 1 vol. de 176 pags. + 1 de Erratas", sem indicar onde o consultou ${ }^{44}$. A Carta no 15 refere-se às Observações sobre as affecções catarrhaes por Cabanis. Traducção do francez por José Lino Coutinho, impresso em 1816, do qual existe um exemplar na Brasiliana Guita e José Mindlin. Esses livros médicos são importantes registros das transformações pelas quais passava a Capitania da Bahia, incluíndo a criação de uma Escola de Cirurgia por D. João VI, da qual faziam parte, sem exceção, todos os autores e tradutores dessas obras.

Do manuscrito apresentado na Carta $\mathrm{n}^{\circ} 13$, Rudimentos Grammaticaes, Portuguezes e Latinos; ou Lição Proveitosa para as Escolas, e geralmente para todos da Nação, de autoria de Bernardo José da Costa e Aragão, (ver Anexo) não conhecemos nenhum exemplar, mas sabemos que foi impresso os devido ao anúncio na Idade d'Ouro de 19 de novembro de 1816. A Carta $\mathrm{n}^{\circ} 14$ (ver Anexo) aponta o manuscrito do Tableau Historique, de la Conspiration des Marechaux de France contre Louis $X V I I I$. Esse é o único livro da primeira fase da Tipografia de Serva que tivera o título em língua francesa. Também não conhecemos exemplar dele, mas foi certamente impresso, já que fora anunciado para venda na Idade d'Ouro de 02 de dezembro de 1817.

As Cartas no 6 e 9 (ver Anexo) demonstram que alguns manuscritos demoravam cerca de três ou quatros anos entre o exame pela Comissão de Censura e o prelo. A Carta $\mathrm{n}^{\circ} 6$ indica o envio de um manuscrito a 4 de julho de 1812, referente ao Novo Methodo de fazer o Açucar ou Reforma Geral Economica, dos Engenhos do Brazil, que contava 89 páginas, uma carta do autor a D. João VI, a prefacção e 6 estampas desdobráveis ${ }^{45}$. O manuscrito demorou mais de quatro anos para sair à luz, o que ocorreu a 18 de outubro 1816, conforme indicado na edição de a Idade d'Ouro do Brazil daquela data. Seu autor Manoel Jacinto de Sampaio e Mello, natural da Bahia, nascido em 1774, era bacharel em direito pela universidade de Coimbra, professor régio de Filosofia na cidade de Lamego, que retornou ao Brasil para dedicar-se à lavoura, sendo proprietário de engenho no termo da vila de Cachoeira.

A Carta $n^{\circ} 9$ refere-se ao manuscrito de autoria do Capitão Theodoro José Guilherme de Sá, intitulado Memoria sobre os conhecimentos necessarios a hum official militar, que, enviado para a Comissão em 1813, só seria impresso com 80 páginas em $1816^{46}$. Não há uma explicação para tamanha demora nessas publicações, mas é pouco provável que tenha havido algum impedimento por parte da Comissão de Censura. O livro de Sampaio e Mello, por exemplo, tem conteúdo muito parecido com os livros impressos sob a direção de José Mariano da Conceição Veloso na Tipografia do Arco do Cego em Lisboa, entre 1799 e 1801, sendo inclusive distribuídos pelo governo nos territórios ultramarinos. Uma hipótese plausível é a dificuldade fi-

\footnotetext{
Castro, 1969: 104-105.

Mello, 1816.

Sá, 1816 .
} 
nanceira que atingiu a Tipografia de Serva entre fins de 1813 e abril de 1815, ocasião em que o empresário buscou um empréstimo de 4 contos de réis, junto ao governo, para expandir seus negócios ${ }^{47}$. A confecção das estampas de o Novo Methodo de fazer o Açucar também pode ter atrasado a sua publicação.

As Cartas n 10, 26 e 28 (ver Anexo) apresentaram à censura as obras teatrais da autoria de Antonio Xavier Ferreira de Azevedo (1784-1814), respectivamente, a tragédia Sophia e Wilcester, o drama Sensibilidade no Crime e a comédia Dever e Natureza. Escondendo o nome com as iniciais A.X.F.A., Azevedo já publicara na Bahia em 1812 o livro Palafox em Saragoça, pela Tipografia de Serva. Um dos autores teatrais de maior sucesso em Portugal, foi retirado de cena por "uma febre teimosa, que em breve degenerou em phtysica, provocada por sua intemperança nos prazeres amorosos". O jovem dramaturgo morreu a 18 de janeiro de 1814, precocemente aos 30 anos. Inocêncio Francisco da Silva conservava cópias de diversos manuscritos de Azevedo, incluindo os três que foram apresentados à censura na Bahia, demonstrando que os mesmos foram bem aceitos e ultracopiados. O bibliógrafo português revelou que "Além d'estas peças impressas [Azevedo] escreveu mais as seguintes, das quaes alumas parece se extraviaram de todo, e d'outras existem copias [manuscritas] em poder de curiosos. Eu possuo algumas. 1657) A Sensibilidade no crime. Drama. 1658) Dever e Naturesa [sic]. 1659) Sophia e Wilcester"48.

A Sensibilidade no Crime chegou a ser representada a 12 de novembro de 1814 , no Teatro Nacional da Rua dos Condes, em Lisboa ${ }^{49}$. Dever e Natureza foi representada no mesmo lugar a 21 de agosto de 1827 e dela ainda existe uma cópia manuscrita na Biblioteca Nacional de Portugal ${ }^{50}$. Essa segunda também foi respresentada no Rio de Janeiro a 6 de janeiro de 1816, no Real Teatro de São João ${ }^{51}$. Esse tipo de obra teatral alcançava bom público e faria a alegria de Manoel Antonio da Silva Serva, que aliás, imprimiu Palafox de maneira furtiva a crer numa nota anônima de 1815:

\begin{abstract}
Sempre me admiro que sendo [Antonio Xavier de Azevedo] este génio hum dos que mais agradou ao público, e deixando já hum tal numero de Peças, apenas se encontra impresso Palafox em Saragoça, mas por modo de furto, ou contrabando impresso na Bahia no papel, em que algum dia se embrulhava o assucar mascavado, pois custa a entender muitas palavras, e só pelo discurso se percebem ${ }^{52}$.
\end{abstract}

Além de Palafox em Saragoça, não há notícias exatas de que qualquer uma dessas três obras de Azevedo, enviadas para a Comissão de Censura, fosse impressa na capital da Bahia ou em outra cidade. Existe, todavia, um anúncio tardio, de 1841, veiculado no Diário de Pernambuco em que foram oferecidas para venda diversas obras de Azevedo, incluído um dos títulos que foram submetidos à censura em Salvador: "As comedias seguintes: Rei Cassimiro, castigo da prepotencia, revolução dos Holandezes em Pernambuco, o patriota escocez, o dever e naturesa, triunfo de N.S., entremezes o padre hipocrita, a ratoeira em que amor pilha, a criada astucioza,

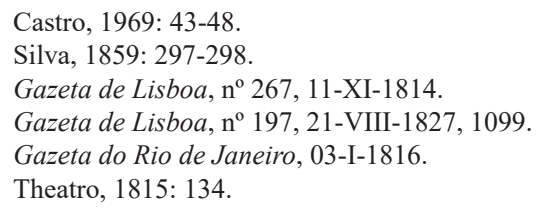


o pinto ambicioso, e a enfermaria dos doudos" $" 53$. Onde e quando foi impresso esse exemplar de Dever e Natureza? Não é possível responder ao presente.

Além dessas obras teatrais, outra questão relevante que surge através da leitura das cartas de censura é a quantidade de livros de filosofia submetidos aos membros da Comissão de Censura entre 1819 e 1821. É notório que a Tipografia de Serva imprimiu apenas dois livros de filosofia, de Eduard Job e Antonio Genovesi (ou Genuense), ambos em 1817, possivelmente por diligência de Ignacio José de Macedo, que então ocupava o cargo de professor substituto da cadeira de Filosofia Moral e Racional. As cartas para aos censores indicam que outros livros de filosofia podem ter sido impressos em Salvador. As Cartas 30 e 33 apresentam a descrição de "Theses Metafísicas". As cartas 35, 37 e 42 indicam a remessa de "Theses" aos censores, sem qualquer outra indicação que torne possível saber o título ou a autoria. Há, não obstante, mais livros de filosofia. As cartas 34 e 39 apresentam, respectivamente, a Demonstração de proposição 146 das instituições metafísicas de Genuense e uma Demonstração Explicativa Filosophica. Não há, contudo, outros registros e nenhum exemplar conhecido de livros de filosofia impressos na Tipografia de Serva entre 1819 e 1821.

Há ainda umas "Concluzões de Logica" (Carta no 27, no Anexo) apresentadas para a censura de Francisco Carneiro de Campos a 13 de julho de 1819. Também não foi possível saber se chegou a ser impresso. É conhecido a existência das Concluzões philosophicas de logica, e metaphysica que, debaixo da direcção de fr. Marcellino de Santa Mathildes Bueno offerecem ao exame publico, que Alfredo Vale Cabral afirma terem sido publicadas na Impressão Régia em 1817. Não há registro de que tivesse sido impressa na Bahia, mas é notório que Serva reproduzia os folhetos do Rio de Janeiro.

Outra novidade que surge nas cartas para os censores são duas obras de geometría datadas de 1819. São conhecidas as duas edições do Manual de Engenheiros, ou Elementos de Geometria Pratica, Fortificação de Campanha, em 1812 e 1815, traduzidas pelo bahiense Manuel Ferreira de Araújo Guimarães, pioneiro no Brasil nos estudos e divulgação da Geometria. As Cartas no 25 e 29, de 2 de julho e 16 de novembro de 1819 (ver Anexo), apresentam, respectivamente, uma "These de Geometria" e umas "Proposições de Geometria juntas". Seriam obras didáticas ou de natureza militar? Quem teria sido seus autores? Não foi possível apurar.

Em 12 de junho de 1819 foi submetido ao censor José Francisco Cardoso de Moraes o manuscrito das "Festas Reaes do Tejuco" (Carta $\left.n^{\circ} 24\right)$. O parecer de Cardoso foi favorável e o folheto foi impresso logo em seguida, conforme assevera o cronista mineiro Joaquim Felício dos Santos:

Houve em Tijuco grandes festas no anno de 1818, determinadas por Camara, como uma demonstração de regosijo público, por ocrasião da acclamação de D. João VI e desposorio do principe D. Pedro. Ha uma descripção d'estas festas em um folheto impresso na Bahia no anno de 1819. Ellas dão a conhecer os costumes e idéas do tempo. As festas começárão por uma illuminação geral no dia 28 de Maio, que durou por seis dias. A casa da residencia do intendente [Manoel Ferreira da Câmara], no alto da rua da Gloria, representando um rico palacete, foi a que mais se distinguio. ${ }^{54}$.

Diario de Pernambuco, no 277, 18-XII-1841, 4.

Santos, 1868: 327-330. 
Não foi encontrado nenhum exemplar para exame e, até o presente, somente Joaquim Felício dos Santos fizera menção a esse folheto impresso na Bahia em 1819, transcrevendo grande parte dele nas suas Memorias do Distrito Diamantino (1868). Deve ter sido impresso já pela Tipografia Serva, e Carvalho, decorrente da sociedade constituída com o gênro a partir de 4 de junho de $1819^{55}$. Dois meses depois, a 3 de agosto de 1819, Manoel Antonio da Silva Serva faleceu durante uma viagem ao Rio de Janeiro e a sua viúva Maria Rosa da Conceição herdaria sua parte na empresa, que passou a ser denominada Tipografia da Viuva Serva, e Carvalho (1819-1827). E possivel que o manuscrito das Festas no Tijuco, possivelmente escrito sob anonimato, tenha chegado a Salvador por meio de pessoas ligadas ao intendente Manoel Ferreira da Câmara Bethencout e Sá, já que a casa da sua família foi um dos lugares da celebração e ele era ligado ao círculo de intelectuais que transitava em torno da Tipografia de Serva. Os viajantes alemães Carl F. P. Martius e Johannes von Spix, testemunhas dos festejos no Tijuco, descrevem as seis janelas do palacete dos Ferreira da Câmara, onde foram expostos quadros que representavam o Despotismo, a Aristocracia, a Monarquia, a Democracia, a Anarquia, a Justiça, a Clemência, o Reino Unido, o Casamento e o Amor Conjugal ${ }^{56}$.

A Carta no 40 (Anexo) apresentou um Catalogo de livros Francezes, e Portuguezes, que é um mistério bibliográfico. Não se conhece, até o presente, outro catálogo de livros que tenha sido impresso pela Tipografia Serva, além do acima referido Catalogo dos Livros que se Achão na Bibliotheca Pública, e supostamente o seu suplemento, feitos por diligência do censor Pedro Gomes Ferrão Castelbranco ${ }^{57}$. Manoel Antonio da Silva Serva também publicara, entre agosto e setembro de 1812, um Catalogo de Livros e mais papeis, que se achão á venda na Loja da Gazeta em S. Barbara na Cidade da Bahia, contando sete folhas volantes numeradas encartados entre os números 66 e 73 de a Idade d'Ouro do Brazil, presentes na coleção da Biblioteca Nacional do Rio de Janeiro. O catálogo apresentado à Comissão de Censura data, não obstante, de setembro de 1820. Há duas hipóteses. A primeira, que se trata de um catálogo de livros importados da Europa por Manoel Antonio da Silva Serva, cuja divulgação foi prometida em maio de 1819: "Na loja da gazeta se vende hum grande sortimento de livros Francezes de todas as qualidades, chegados proximamente da França, por preços commodos; e brevemente sahirá o catalogo delles" 58 . A segunda hipótese reside na notícia de que o comerciante de livros José Paulo Franco Lima, um dos mais importantes em Salvador àquela época, e o caixeiro Manoel José Pereira Coimbra publicaram em Paris um Catalogo dos livros portuguezes, latinos e francezes que se achão à venda em caza de M. J. Pereira Coimbra, e na loge de Jose Paulo Franco Lima ao Taboão na Bachia [sic], impresso no ano de 1822, tratandose da lista de livros que disponibilizava na sua loja sita ao Taboão ${ }^{59}$. Manoel José Pereira Coimbra era caixeiro de Manoel Antonio da Silva Serva e respondia pelos seus negócios durante as viagens do empresário ${ }^{60}$. Também não foi possível localizar nenhum exemplar da edição parisiense do Catálogo dos livros portugueses, latinos e francezes mas seu título apresenta significativas semelhanças com o manuscrito

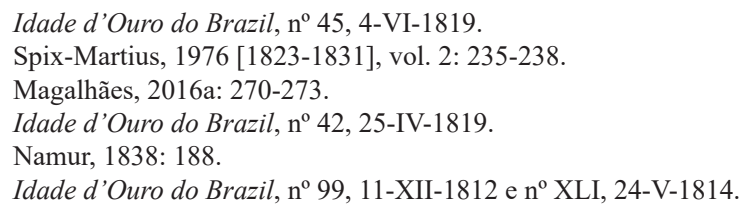


enviado para censura em setembro de 1820. Seria, então, o catálogo francês de 1822 uma reprodução do impresso baiano de fins de 1820? Essa questão só pode ser respondida se os exemplares forem localizados.

A Carta $\mathrm{n}^{\circ} 41$, enviada para a censura em outubro de 1820, apresentou uma tradução de autoria de Eusébio Vanério, intitulado Manual do Systema da Sociedade da Escola Britanica \& Estrangeira de Londres: para ensinar lêr, escrever, arithmetica e trabalhos d'agula nas Escolas Elementares segundo o Methodo do Ensino Mutuo inventado por Mr. Lancaster, cuja edição inglesa foi publicada por Joseph Lancaster quatro anos antes ${ }^{61}$. Não encontramos exemplar impresso, mas foi possível encontrar o manuscrito no Arquivo Nacional do Rio de Janeiro, que Vanério remeteu a D. João VI, em meados de 1819. Em anexo está um ofício emitido pela direção da British and Foreigh School Society, encaminhado a Vanério, em que se registraram recomendações satisfatórias sobre a introdução do Sistema Inglês na Bahia ${ }^{62}$.

Em torno de 1820 o sistema de ensino mútuo de Joseph Lancaster se expandiu no do Império português. Em 1819 o ensino mútuo foi introduzido na ilha da Madeira pelo britânico Joseph Phelps e por Alexandre Luís da Cunha. Há notícia de que no Funchal, em 1821, foi escrito um Breve Esboço do Sistema Britânico de Educação ${ }^{63}$. O pionerismo da implantação desse sistema caberia, contudo, a Vanério, que era segundo Sacramento Blake natural da ilha da Madeira, mas fez sua carreira política na Bahia e em Sergipe. Em Salvador, foi diretor do Colégio Constituição à época em que submeteu à censura o manuscrito Manual do Systema da Sociedade da Escola Britanica. Na sessão de 7 de agosto de 1821 das Cortes Geraes, em Lisboa, há a seguinte notícia:

Deu conta o mesmo senhor Secretario do offerecimento que faz ás Cortes o cidadão Euzebio Vanerio, Director do Collegio denominado Constituição em a cidade da Bahia, de uma traducção do inglez do systema da sociedade da Escola britanica e estrangeira de Londres, para ensinar a ler, escrever, arithmetica, e trabalhos de agulha nas escolas elementares, segundo o methodo do ensino mutuo, inventado por Lencastre; o que foi recebido com agrado, e se remetteu á Commissão de Instrucção publica ${ }^{64}$.

É possível que Vanério tenha entregue à Comissão de Instrução Pública um exemplar impresso na Tipografia da Viuva Serva, e Carvalho. Localizar esse impresso seria importante para a História da Educação no Brasil.

A correspondência revela uma Carta da autoria de Cristo, Bastos e Filgueiras, diretores da Companhia de Seguros Conceito Público. As primeiras sociedades de seguros da Bahia datam de 1808, quando foram fundadas por Carta Régia de 9 de junho e 24 de outubro, respectivamente, a Boa Fé e a Conceito Público, que asseguravam os navios que transitavam pelo Porto de Salvador. Nenhum exemplar dessa carta foi localizado. Duas traduções apresentadas em 1818 à Comissão são identificáveis e delas podem ser encontrados exemplares impressos. A primeira, Carta $\mathrm{n}^{\circ}$

$61 \quad$ Lancaster, 1816.

62 Manual do Systema da Sociedade da Escola Britanica, traduzido por Eusébio Vanério. Bahia, 1820. ANRJ, cód. 807, v.12, ff. 234-332.

63 Relatório dos Progressos da Escola Lancasteriana na Provícia da Madeira. Madeira, 1820. AHU, Madeira, Cx. 21, D. 7021. Breve Esboço do Sistema Britânico de Educação. Madeira, 1821. AHU, Madeira, Cx 22. D. 7323.

64 Portugal, 1821: 1099. 
18, é a Economia da Vida Humana, impressa em Portugal desde o século XVIII e, a segunda, Carta $n^{\circ} 19$, é a tradução da obra clássica de Horacio Flacco feita pelo médico Antonio José de Lima Leitão ${ }^{65}$. Não foi possível identificar outros manuscritos indicados nas cartas aos censores, à exemplo das de $n^{\circ} 31$ e 32, respectivamente, um "Compromisso" e uma "Falla traduzida do Idioma Inglez".

No conjunto, foram registrados apenas três impressos de natureza religiosa, nas cartas $n^{\circ} 22,38$ e 43 (ver Anexo), sendo todos os três examinados por Francisco Carneiro de Campos no triênio de 1819-1821. O primeiro foi a "Oração gratulatoria", remetida a 22 de maio de 1819. Trata-se de um folheto da autoria de frei João do Amor Divino Quirino, intitulado Oração gratulatoria pelo faustissimo nascimento da serenissima senhora princeza da Beira ${ }^{66}$. A "Oração de Ação de Graças", apresentada a 12 de agosto de 1820, deve ser a Oração recitada por fr. Francisco Xavier de Santa Rita Bastos no Te Deum Solemne em acção de graças pelo decreto de 24 de fevereiro, impressa no ano seguinte ${ }^{67}$. A "Pastoral do Bispo Eleito do Pará", penúltimo manuscrito a ser submetido aos censores, a 3 de janeiro de 1821, foi impresso e dele existe um exemplar na Biblioteca Guita e José Mindlin ${ }^{68}$.

O último manuscrito submetido à censura foi um "Discurso" remetido a José Francisco Cardoso de Moraes a 11 de janeiro de 1821, que foi impresso com o titulo de Discurso pronunciado na sala das cortes, na sessão de 5 de abril por hum dos illustres deputados do Pará, na Tipografia da Viuva Serva, e Carvalho, com 4 páginas $^{69}$. O último livro da Tipografia da Viúva Serva a estampar "Com licença da commissão da censura" foi, possivelmente, Lembranças uteis tendentes a melhor reforma que o Brazil procura pela constituição. Por J.V.S, também da Tipografia da Viuva Serva, e Carvalho ${ }^{70}$.

Em 1821 as luzes da Revolução Constitucional e Liberal do Porto alcançaram a Bahia e, gradualmente, afastaram as sombras da censura. O Governo Interino em Lisboa, dirigido pelo pedreiro-livre Felipe Ferreira de Araújo e Castro, amigo de Hipólito José da Costa e de Diogo Soares da Silva e Bivar, estabeleceu novos critérios que enfraqueceram o antigo aparato censorial português. De acordo com o texto:

O Governo Interino estabelecido em Lisboa manda, que a Commissão de Censura nomeada por Portaria na data d'este se regule no sentido da primeira Proclamação do mesmo Governo de 17 do corrente, tendo em vista os principios adoptados unanimemente por toda a Nação Portugueza, de sermos fieis á Religião Catholica Romana, a ElRei Nosso Senhor, Sua Augusta Dynastia, e a Constituição, que hão de fazer os Representantes da Nação em Cortes, devendo a mesma Commissão ter em particular consideração, que a Impressão não seja vehiculo de paixões particulares, e de principios subversivos da ordem, e tranquilidade pública, nem de doutrinas, ou ainda expressões, que possão alterar a Harmonia, e Relação politicas, que felizmente subsistem com as outras Nações, mas sim hum meio de illustrar o verdadeiro Patriotismo, e de consolidar a moderação, fraternidade, e generoso

\footnotetext{
Economia, 1818; Leitão, 1818.

Quirino, 1819. Exemplar na Biblioteca da Universidade Federal do Recôncavo Baiano [Brasil].

Bastos, 1821.0 único exemplar conhecido está na Seção de Obras Raras da Biblioteca Nacional do Rio de Janeiro (em diante BNRJ) [Brasil], 37,0,2 $\mathrm{n}^{\circ} 8$.

68 Coelho, 1821. Exemplar na Biblioteca Brasiliana Guita e José Mindlin [Brasil], na USP, registro nº 002381542.

69 Exemplar na Seção de Obras Raras da BNRJ OR099A,009,002/MFN11087.

70 Exemplar na Seção de Obras Raras da BNRJ OR096,002,040/MFN13436.
} 
esquecimento dos males passados. O que participo a V. m. por ordem mesmo Governo $=$ Deos guarde a V. m. Palacio do Governo em 21 de Setembro de 1820. = Filippe Ferreira de Araujo e Castro. Senhores Sebastião Francisco Mendo Trigozo, Reverendo Lucas Tavares, Pedro José de Figueiredo, e José Portelli. Está conforme, José Caetano de Paiva Pereira ${ }^{71}$.

O último suspiro da Comissão de Censura na Bahia veio da subserviente Junta Provisória estabelecida em 1821, da qual ainda fez parte o censor José Fernandes da Silva Freire. A partir de 16 de Fevereiro daquele ano a Idade d'Ouro do Brazil, entre seus números 15 e 21, foi impressa "Com Permissão do Governo Provisional". A portaria que confirmou a manutenção da censura, de acordo com as intruções acima, foi publicada no número 22 daquela gazeta:

Por quanto nas actuaes circunstancias se faz necessario facilitar a impressão, e leitura dos bons livros, e papeis Nacionaes e Estrangeiros, assim para que o público tenha conhecimento dos sucessos importantes, como para que por meio das idéas solidas e uteis se dirija e rectifique a opinião publica, guardados os lemites de huma bem entendida liberdade civil, que por ora não póde deixar que assente sobre principios liberaes: Por estas e outras considerações a Junta Provisional do Governo desta Provincia ha por bem crear huma Commissão que se denominará: Comissão de Censura. São para ella nomeados o Desembargador Francisco Carneiro de Campos, o Desembargador Joaquim Ignacio Silveira da Motta, e Diogo Soares da Silva e Bivar. Sem a licença de hum dos Membros desta Commissão se não poderão imprimir quaesquer Gazetas, periodicos, livros, e mais papeis que se queirão offerecer á estampa; e bem assim sem a referida licença se não admittirão a despacho os livros que vierem do Estrangeiro. A Comissão para conceder ou denegrar estas licenças se regularápelas instrucções dadas ao Officio do Governo Supremo de Lisboa de 21 de Setembro proximo passado, e pubicado na Gazeta d'aquella Capital de 23 do mesmo mez e anno. José Caetano de Paiva Pereira, Membro do Governo, e Secretario do Interior e Fazenda o tenha assim entendido, e o faça executar, enviando ás Estações a que pertencer a devida participação. Palacio do Governo em 19 de Fevereiro de 1821. Com nove Rubricas dos Membros da Junta do Governo ${ }^{72}$.

Não deixa de ser curioso que o inconfidente Diogo Soares da Silva e Bivar, personagem que teve o primeiro manuscrito censurado na Bahia em 1811, dez anos depois, foi nomeado membro da nova Comissão de Censura. Após a portaria supra, não foi registrado mais nenhuma carta submetendo livros à censura na Bahia, mas os números 22, 23 e 24 da Idade d'Ouro do Brazil voltaram a ser impressos "Com licença da Comissão de Censura". A partir do número 25, de 28 de fevereiro de 1821 , aquele jornal, bem como os outros títulos da Tipografia de Serva e Carvalho, passaram a circular "Com Permissão do Governo Provisional".

A 2 de março de 1821, um decreto de D. João VI -às vésperas de retornar para Lisboa- abolira a censura prévia de manuscritos e estabeleceu os princípios para a

Gazeta de Lisboa, no $299,23-\mathrm{IX}-1820,5$.

72 Idade d'Ouro do Brazil, $\mathrm{n}^{\circ} 22,24-\mathrm{II}-1821,2-3$. 
liberdade de imprensa ${ }^{73}$. Decreto ambíguo que, na prática, desobrigava a censura dos manuscritos, mas não a apresentação das provas tipográficas. Em 5 de junho de 1821 , o regente D. Pedro colocou em vigor a lei que regulamentaria a liberdade de imprensa, complementada em 28 de agosto de 1821, na qual foi observado que, "pretendendo evitar que os autores ou editores encontrassem inesperados estorvos à publicação dos seus escritos, era [...] servido mandar que se não embarace por pretexto algum a impressão que se quiser fazer de qualquer escrito, devendo unicamente servir de regra o que as mesmas Cortes têm determinado sobre este objeto" 74 .

O maço 173 (1820-1821) do APEB encerrou seus registros em fevereiro de 1821 e daquela data em diante não foi possível encontrar mais cartas do governo submetendo manuscritos aos membros da Comissão de Censura na Bahia. Após a posse da segunda Junta de Governo da Bahia, ocorrida a 2 de fevereiro de 1822, seu presidente Francisco Vicente Vianna determinou a extinção da Comissão de Censura, que teve lugar a 4 de fevereiro. Com a extinção definitiva daquela Comissão, os impressos bahienses estavam livres da obrigação de estampar "Com as licenças necessárias" ou "Com Permissão do Governo Provisional”. As sombras da censura já não eram mais legítimas na Província da Bahia.

\section{Referências bibliográficas}

Abreu, Márcia. "La libertad y el error: la acción de la censura luso-brasileña (17691834)". Cultura Escrita \& Sociedad, vol. 7 (2008a): 118-141.

— "Um leitor muito peculiar: José Antonio de Miranda, censor régio". Escritos (Revista da Fundação Casa de Rui Barbosa), vol. 2 (2008b): 35-48.

Algranti, Leila Mezan. "Política, religião e moralidades: a censura de livros no Brasil de d. João VI (1808-1821)". Em Minorias silenciadas: história da censura no Brasil, Tucci Carneiro, Maria Luiza (org.). São Paulo: Edusp: 2002, 91-119.

Almanach. Almanach para a Cidade da Bahia anno 1812. Bahia: na Typ. de Manoel Antonio da Silva Serva, 1811.

Atalá. Atalá ou os amores de dous selvagens no deserto, por Francisco Augusto Chateaubriand. Traduzido na linguagem portugueza por ***. Bahia: Na Typog. de Manoel Antonio da Silva Serva, 1819.

Bastos, Francisco Xavier. Oração recitada por fr. Francisco Xavier de Santa Rita Bastos no Te Deum Solemne... em acção de graças pelo decreto de 24 de fevereiro. Bahia: na Typographia da Viúva Serva, e Carvalho, 1821.

Biblioteca Nacional do Rio de Janeiro (ed). Documentos Históricos da Biblioteca Nacional, vol. CII. Rio de Janeiro: A. Porto \& C., 1953.

Bocage, Manuel Maria Barbosa du. Rimas. Lisboa: Simão Thaddeo Ferreira, 1799.

- As Plantas, Poema de Ricardo de Castel. Lisboa: na Typographia do Arco Cego, 1801.

Brito, João Rodrigues de. Cartas economico-politicas sobre a agricultura, e commercio da Bahia. Lisboa: Imprensa Nacional, 1821.

73 D. João VI, 1821. Exemplar que consta no catálogo da Biblioteca da UFRB, mas que durante as pesquisas não foi localizado.

74 Gazeta do Rio de Janeiro, $\mathrm{n}^{\circ}$ 79, 01-IX-1821, 1. 
Castro, Renato Berbert de. A primeira imprensa da Bahia e suas publicações: A Tipografia de Manoel Antonio da Silva Serva: 1811-1819. Salvador: Secretaria de Educação e Cultura, 1969.

Coelho, Romualdo. Pastoral. Bahia: na Typographia da Viúva Serva e Carvalho, 1821.

Costa e Silva, Cândido da. Os Segadores e a Messe: o clero na Bahia oitocentista. Salvador: EDUFBA, 2000.

Economia. Economia da vida humana obra traduzida de hum Manuscrito Indiano, escripta por hum antigo Bramano. Bahia: Typ. de Manoel Antonio da Silva Serva, 1818.

D. João VI. Decreto Dom João estabelecendo a liberdade de imprensa. Bahia: Typographia da Viúva Serva, e Carvalho, 1821.

Lancaster, Joseph. Manual of the System of the British and Foreign School Society of London, for teaching, reading, writing, arithmetic, and needle-work, in the elementary schools. London: Longman and Co., 1816.

Leitão, Antonio José de Lima. Arte Poetica de Q. Horacio Flacco, Epistola aos Pisões, traduzida em verso portuguez. Bahia: Typ. de Manoel Antonio da Silva Serva, 1818.

Luna, Lino do Monte Carmello. Memória Histórica e Biográfica do Clero Pernambucano. Recife: Tipografia de F. C. de Lemos e Siva, 1857.

Macedo, Ignacio José de. $O$ Velho Liberal do Douro, $\mathrm{n}^{\circ} 34$. Lisboa: Typografia da Rua dos Fanqueiros, 1833.

Magalhães, Pablo A. Iglesias. 'Ignacio José de Macedo: Da Idade D’Ouro ao Velho Liberal do Douro". Revista do Instituto Geográfico e Histórico da Bahia, vol. 108 (2013), 221-262.

- "Livros Ultramarinos: O Comércio de Servinas em Portugal". Revista Portuguesa de História do Livro, vol. 29-30 (2014), 433-467.

— "A Parafraze dos Proverbios de Salomão: O código moral dos pedreiros livres impresso na Bahia em 1815". Revista Portuguesa de História do Livro, vol. 3536 (2015), 369-419.

- "Adendo ao Catálogo de Livros Impressos na Tipografia de Manoel Antonio da Silva Serva (1811-1819): Complemento ao livro A Primeira Imprensa na Bahia e suas publicações de Renato Berbert de Castro (1969)". LIVRO, vol. 6, (2016a), 253-280.

- "As servinas em Portugal: a rede comercial intercontinental de livros impressos na Bahia colonial”. Topoi: revista de historia, vol. 17 (2016b), 223-256. DOI: $10.1590 / 2237-101 \times 0173212$

- "O Tradutor dos Abomináveis Princípios: José Pedro de Azevedo Sousa da Câmara e a circulação dos escritos de Voltaire em Portugal e no Brasil (17901834)". Historia (UNESP. Assis), vol. 35 (2016c), 1-40. DOI: 10.1590/1980436920160000000101

Mello, Manoel Jacintho de Sampaio e. Novo methodo de fazer o açucar ou reforma geral economica, dos engenhos do Brazil. Bahia: Typog. de Manoel Antonio da Silva Serva, 1816.

Mendonça, Hipólito José da Costa Furtado de. "Liberdade de Imprensa". Correio Braziliense, vol. XXVI, n 157 (junho de 1821), 662-666.

Moraes, Rubens Borba de. Livros e Bibliotecas no Brasil Colonial. São Paulo: Secretaria da Cultura, 1979. 
Muller, Christiano. Memoria Historica sobre a Religião na Bahia. Bahía: Imprensa Oficial do Estado, 1923.

Namur, Jean Pie. Bibliographie paleographico-diplomatico-bibliologique générale ou répertore systématique, tomo iii. Liége: P. J. Collardin, Imprimeur de 1'Université et Libraire, 1838.

Neves, Lúcia Maria Bastos Pereira das - Bessone, Tânia Bessone. "O medo dos "abomináveis princípios franceses": a censura dos livros nos inícios do século XIX no Brasil”. Acervo: Revista do Arquivo Nacional, vol. 4, n 1, (jan.-jun. (1989), 113-119.

Oliveira Marques, António Henrique de. História da Maçonaria em Portugal, vol. 1. Lisboa: Presença, 1990.

Pereira, Ângelo. D. João VI, Príncipe e Rei, vol. iii. Lisboa: Imprensa Nacional de Publicidade, 1956.

Portugal. Diario das Cortes Geraes e Extraordinarias da Nação Portugueza: Abril 5, 1821-Junho 8. Lisboa: Impressão Régia, 1821.

Quirino, João do Amor Divino. Oração gratulatoria pelo faustissimo nascimento da serenissima senhora princeza da Beira. Bahia: Typ. da Viuva Serva e Carvalho, 1819.

Sá, Theodoro José Guilherme de. Memoria sobre os conhecimentos necessarios a hum official militar. Bahia: Typ. de Manoel Antonio da Silva Serva, 1816.

Santos, Joaquim Felício. Memorias do Distrito Diamantino. Rio de Janeiro: Typographia Americana, 1868.

Silva Bastos, José Timóteo da. História da censura literária em Portugal. Coimbra: Imprensa da Universidade, 1926.

Silva, Innocencio Francisco da. Diccionario Bibliographico Portuguez, vol. I. Lisboa: Imprensa Oficial 1859.

Spix, Johann Baptist von - Martius, [Karl Friedrich Philipp von. Viagem pelo Brasil: 1817-1820 [1823-1831], 3 vols. São Paulo: Edições Melhoramentos, 1976.

Theatro. Theatro de Manoel de Figueiredo, tomo xiv. Lisboa: Na Impressão Régia, 1815.

Ventin Pereira, José Augusto. Los primeros cien años de la empresa informativa en Bahia. Madrid: Fraguar Editorial, 1997.

Villalta, Luiz Carlos. "Censura literária e inventividade dos leitores no Brasil colonial". Em Minorias silenciadas: história da censura no Brasil, Tucci Carneiro, Maria Luiza (org.). São Paulo: Edusp, 2002, 45-89.

\section{Anexos: Cartas do Governo para os censores conservadas no Arquivo Público do Estado da Bahia (APEB)}

Na transcrição abaixo foi seguida a sequência cronológica registrada nos seis maços do APEB. Foi adotado quatro situações para identificação dos manuscritos censurados: IMP - Impresso, de que se conhece exemplar; INE - Impresso, mas que não se conhece exemplar; NPI - Não é possível afirmar que foi impresso; NTM - As Cartas no 5 e 7 que não apresentaram o título do manuscrito. 
Tabla. 1. Cartas do Governo para os censores.

\begin{tabular}{|c|c|c|}
\hline $\begin{array}{l}\mathbf{N}^{\circ} / \\
\text { Status }\end{array}$ & $\begin{array}{l}\text { NÚMERO DO MAÇO / FO- } \\
\text { LHAS }\end{array}$ & CONTEÚDO DA CARTA \\
\hline $\begin{array}{l}1 \\
\text { IMP }\end{array}$ & $\begin{array}{l}\text { APEB } \\
\text { Seção Colonial/Provincial } \\
\text { Cartas do Governo, maço } 166 \\
(1809-1811), \text { fl. } 329 .\end{array}$ & $\begin{array}{l}\text { P.a o Coronel Pedro Gomes Ferrão Castelbranco } \\
\text { Remetto a V. S.a o Manuscripto incluzo = Principios } \\
\text { Geraes, ou verdadeiro Methodo para se aprender } \\
\text { a ler, e a pronunciar com a propried.e, a Lingua } \\
\text { Franceza = para que informe, se julga digno de dar- } \\
\text { se ao prelo. D.s G.e a V. S.a B.a } 22 \text { de Maio de } 1811 . \\
\text { Conde dos Arcos. Sr. Coronel Pedro Gomes Ferrão } \\
\text { Castelbranco. }\end{array}$ \\
\hline $\begin{array}{l}2 \\
\text { IMP }\end{array}$ & $\begin{array}{l}\text { APEB } \\
\text { Seção Colonial/Provincial } \\
\text { Cartas do Governo, maço } 166 \\
(1809-1811), \text { fl. 341v. }\end{array}$ & $\begin{array}{l}\text { P.a o Dez.or Joze Rodrigues de Brito } \\
\text { Remetto a VM.ce o Manuscripto incluzo = Princip- } \\
\text { ios Geraes sobre a Legislação = para que informe, } \\
\text { se julga digno de dar se ao prelo. D.s G.e VM.ce B.a } \\
10 \text { de Junho de } 1811 \text {. Conde dos Arcos. P.a o Dez.or } \\
\text { João Rodrigues de Brito. }\end{array}$ \\
\hline $\begin{array}{l}3 \\
\text { NPI }\end{array}$ & $\begin{array}{l}\text { APEB } \\
\text { Seção Colonial/Provincial } \\
\text { Cartas do Governo, maço } 167 \\
(1810-1811), \text { fls. } 311 v-312 .\end{array}$ & $\begin{array}{l}\text { P.a Jozé Francisco Cardozo } \\
\text { VM.ce me informará, se julga digno de dar se ao pre- } \\
\text { lo o Manuscripto junto que contem o Canto heroico, } \\
\text { ao Natalicio do Principe Regente Nosso S.r, pelo } \\
\text { D.r João da Costa Carneiro de Oliveira. D.s G.e } \\
\text { VM.ce B.a } 20 \text { julho de } 1811 \text {. Conde dos Arcos. P.a } \\
\text { Jozé Francisco Cardozo }\end{array}$ \\
\hline $\begin{array}{l}4 \\
\text { IMP }\end{array}$ & $\begin{array}{l}\text { APEB } \\
\text { Seção Colonial/Provincial } \\
\text { Cartas do Governo, maço } 167 \\
(1810-1811), \text { fl. } 327 .\end{array}$ & $\begin{array}{l}\text { P.a o Professor Jozé Francisco Cardozo } \\
\text { Remetto a VM.ce, o Manuscripto incluzo, intitulado } \\
=\text { Elementos de Osteologia Pratica, para que VM.ce } \\
\text { o examine, se nelle se não conthem, couza que obste, } \\
\text { o dar se a prelo. D.s G.e a VM.ce B.a a } 20 \text { de Agosto } \\
\text { de } 1811 \text {. Conde dos Arcos. Sr. Professor Jozé Fran- } \\
\text { cisco Cardozo }\end{array}$ \\
\hline $\begin{array}{l}5 \\
\text { NTM }\end{array}$ & $\begin{array}{l}\text { APEB } \\
\text { Seção Colonial/Provincial } \\
\text { Cartas do Governo, maço } 168 \\
(1811-1814), \text { fl. } 96 .\end{array}$ & $\begin{array}{l}\text { P.a Jozé Francisco Cardozo } \\
\text { Vm.ce me informe, se acha digno de dar se ao Prelo, o } \\
\text { Manuscripto junto. D.s G.e a VM.ce B.a } 4 \text { de Abril de } \\
\text { 1812. Conde dos Arcos. S.r Jozé Francisco Cardozo }\end{array}$ \\
\hline $\begin{array}{l}6 \\
\text { IMP }\end{array}$ & $\begin{array}{l}\text { APEB } \\
\text { Seção Colonial/Provincial } \\
\text { Cartas do Governo, maço } 168 \\
(1811-1814), \text { fl. } 126 .\end{array}$ & $\begin{array}{l}\text { P.a o coronel Pedro Gomes Ferrão } \\
\text { Informe VS.a, se julga digno de se dar ao Prelo, o } \\
\text { Manuscripto junto intitulado Novo Methodo de faz- } \\
\text { er o Assucar. D.s G.e a V.S.a B.a } 4 \text { de Julho de } 1812 . \\
\text { Conde dos Arcos. S.r Coronel Pedro Gomes Ferrão } \\
\text { CastelBranco }\end{array}$ \\
\hline $\begin{array}{l}7 \\
\text { NTM }\end{array}$ & $\begin{array}{l}\text { APEB } \\
\text { Seção Colonial/Provincial } \\
\text { Cartas do Governo, maço } 168 \\
(1811-1814), \text { fl. 207v. }\end{array}$ & $\begin{array}{l}\text { P.a o Professor Jubilado Jozé Francisco Cardozo } \\
\text { VM.ce me declare, com a possivel brevd.e, se o Man- } \\
\text { uscripto junto, esta nas circunstancias de dar se ao } \\
\text { prelo. D.s G.e a VM.ce B.a } 5 \text { de Fevereiro de } 1813 . \\
\text { Conde dos Arcos. S.r Professor Jubilado Jozé Fran- } \\
\text { cisco Cardozo. }\end{array}$ \\
\hline
\end{tabular}




\begin{tabular}{|c|c|c|}
\hline $\begin{array}{l}8 \\
\text { IMP }\end{array}$ & $\begin{array}{l}\text { APEB } \\
\text { Seção Colonial/Provincial } \\
\text { Cartas do Governo, maço } 168 \\
(1811-1814), \text { fl. } 218 \mathrm{v} .\end{array}$ & $\begin{array}{l}\text { P.a Jozé Francisco Cardozo Proffessor Jubilado } \\
\text { VM.ce me informe, se julga digno de dar se ao prelo } \\
\text { o Manuscripto junto, intitulado= Memorias Physio- } \\
\text { logicas, e Praticas. B.a } 15 \text { de Março de } 1813 \text {. Conde } \\
\text { dos Arcos. Sr. Proffessor Jubilado Jozé Francisco } \\
\text { Cardozo }\end{array}$ \\
\hline $\begin{array}{l}9 \\
\text { IMP }\end{array}$ & $\begin{array}{l}\text { APEB } \\
\text { Seção Colonial/Provincial } \\
\text { Cartas do Governo, maço } 168 \\
(1811-1814), \text { fl. } 280 .\end{array}$ & $\begin{array}{l}\text { P.a o Coronel Pedro Gomes Ferrão CastelBranco } \\
\text { Informe V. S.a, se julga digno de dar se ao prelo, o } \\
\text { Manuscripto junto, intitulado Memoria sobre os } \\
\text { Conhecimentos necessários a hum official Militar. } \\
\text { D.s G.e a V. S.a B.a } 4 \text { de Agosto de } 1813 \text {. Conde dos } \\
\text { Arcos. S.r Coronel Pedro Gomes Ferrão Castelbran- } \\
\text { co. }\end{array}$ \\
\hline $\begin{array}{l}10 \\
\text { NPI }\end{array}$ & $\begin{array}{l}\text { APEB } \\
\text { Seção Colonial/Provincial } \\
\text { Cartas do Governo, maço } 168 \\
(1811-1814), \text { fl. } 298 .\end{array}$ & $\begin{array}{l}\text { P.a Jozé Francisco Cardozo } \\
\text { VM.ce me informe, se julga digno de dar se ao prelo } \\
\text { a Tragedia em manuscripto junto, intitulado Sophia. } \\
\text { D.s G.e a VM.ce B.a } 15 \text { de Setembro de } 1815 \text {. Conde } \\
\text { dos Arcos. S.r Jozé Francisco Cardozo. }\end{array}$ \\
\hline $\begin{array}{l}11 \\
\text { IMP }\end{array}$ & $\begin{array}{l}\text { APEB } \\
\text { Seção Colonial/Provincial } \\
\text { Cartas do Governo, maço } 168 \\
(1811-1814), \text { fl. } 307 \mathrm{v} .\end{array}$ & $\begin{array}{l}\text { P.a o Coronel Pedro Gomes Ferrão } \\
\text { V. S. informe, se julga digno de dar se ao prelo, o } \\
\text { manuscripto junto, intitulado Tratado de Anatomia. } \\
\text { D.s G.e a V. S.a B.a } 18 \text { de Outubro de } 1813 \text {. Conde } \\
\text { dos Arcos. Sr. Coronel Pedro Gomes Ferrão. }\end{array}$ \\
\hline $\begin{array}{l}12 \\
\text { INE }\end{array}$ & $\begin{array}{l}\text { APEB } \\
\text { Seção Colonial/Provincial } \\
\text { Cartas do Governo, maço } 169 \\
(1814-1817) \text {, fl. } 94 .\end{array}$ & $\begin{array}{l}\text { P.a Jozé Francisco Cardozo } \\
\text { Envio a VM.ce o Manuscripto junto, intitulado = } \\
\text { Filosophia Quimica, ou Verdades Fundamentaes, } \\
\text { sobre a Quimica, e Medicina; para que me informe, } \\
\text { se está nos termos, de dar se ao prelo. D.s G.e a } \\
\text { VM.ce. B.a } 18 \text { de Março de 1815. Conde dos Arcos. } \\
\text { S.r Joze Franc.o Cardozo. }\end{array}$ \\
\hline $\begin{array}{l}13 \\
\text { INE }\end{array}$ & $\begin{array}{l}\text { APEB } \\
\text { Seção Colonial/Provincial } \\
\text { Cartas do Governo, maço } 169 \\
(1814-1817), \text { fl. } 230 .\end{array}$ & $\begin{array}{l}\text { P.a o Proffessor Jubilado Jozé Francisco Cardozo. } \\
\text { Remetto a VM.ce o Manuscripto intitulado, Rudi- } \\
\text { mentos Grammaticaes Portuguezes, e Latinos, } \\
\text { para que me informe, se esta nos termos, de dar se } \\
\text { ao prelo. D.s G.e a VM.ce B.a } 18 \text { de Março de } 1816 . \\
\text { Conde dos Arcos. S.r Proffessor Jubilado Jozé Fran- } \\
\text { cisco Cardozo.. }\end{array}$ \\
\hline $\begin{array}{l}14 \\
\text { INE }\end{array}$ & $\begin{array}{l}\text { APEB } \\
\text { Seção Colonial/Provincial } \\
\text { Cartas do Governo, maço } 169 \\
(1814-1817), \text { fls. } 263-263 \mathrm{v}\end{array}$ & $\begin{array}{l}\text { P.a Jozé Francisco Cardozo Proffessor Jubilado. } \\
\text { Envio A VM.ce o Manuscripto Francez incluzo Tab- } \\
\text { leau Historique de Conjuration de La Marechaux } \\
\text { de France, contre Luiz dix huit para que o Reveja, e } \\
\text { informe, se esta nas circunst.as de poder imprimirse. } \\
\text { D.s G.e a VM.ce B.a a } 2 \text { de Julho de } 1816 \text {. Conde dos } \\
\text { Arcos. S.r Proffessor Jubilado Jozé Francisco Cardo- } \\
\text { zo. }\end{array}$ \\
\hline $\begin{array}{l}15 \\
\text { IMP }\end{array}$ & $\begin{array}{l}\text { APEB } \\
\text { Seção Colonial/Provincial } \\
\text { Cartas do Governo, maço } 169 \\
(1814-1817), \text { fl. } 266 .\end{array}$ & $\begin{array}{l}\text { P.a o Proffessor Jubilado Joze Francisco Cardozo. } \\
\text { VM.ce me informe, se o Manuscripto incluzo intitu- } \\
\text { lado Observaçoens sobre as affecçoens Catarraes } \\
\text { em geral esta nas circunstancias de imprimir se. D.s } \\
\text { G.e a VM.ce B.a } 15 \text { de Julho de } 1816 \text {. Conde dos Ar- } \\
\text { cos. S.r Proffessor Jubilado Joze Francisco Cardozo. }\end{array}$ \\
\hline
\end{tabular}




\begin{tabular}{|c|c|c|}
\hline \begin{tabular}{|l|}
16 \\
IMP
\end{tabular} & $\begin{array}{l}\text { APEB } \\
\text { Seção Colonial/Provincial } \\
\text { Cartas do Governo, maço } 170 \\
(1817-1819), \text { fl. } 145 .\end{array}$ & $\begin{array}{l}\text { P.a Jozé Francisco Cardozo. } \\
\text { Envio a VM.ce o Manuscripto junto intitulado = Ata- } \\
\text { lá ou os Amores de dois Selvagens no Deserto = p.a } \\
\text { q. me informe se está nas circunstancias de permitir } \\
\text { q. se dê ao prelo. Deos G.e a VM.ce B.a } 20 \text { de Julho } \\
\text { de } 1817 \text {. Conde dos Arcos. S.r Proff.or Joze Franc. } \\
\text { co Cardozo. }\end{array}$ \\
\hline $\begin{array}{l}17 \\
\text { NPI }\end{array}$ & $\begin{array}{l}\text { APEB } \\
\text { Seção Colonial/Provincial } \\
\text { Cartas do Governo, maço } 170 \\
(1817-1819), \text { fl. } 168 \mathrm{v} .\end{array}$ & $\begin{array}{l}\text { P.a o Proffessor Jubilado Joze Francisco Cardozo } \\
\text { Envio a VM.ce o Manuscripto junto, para que exa- } \\
\text { minando a Tradução Portugueza, diga se esta em } \\
\text { termos de se poder imprimir. D.s G.e a VM.ce B.a } 6 \\
\text { de Fevereiro de } 1818 \text {. Conde da Palma. S.r Proffessor } \\
\text { Jubilado Joze Francisco Cardozo. }\end{array}$ \\
\hline $\begin{array}{l}18 \\
\text { IMP }\end{array}$ & $\begin{array}{l}\text { APEB } \\
\text { Seção Colonial/Provincial } \\
\text { Cartas do Governo, maço } 170 \\
(1817-1819), \text { fl. } 217 \mathrm{v} .\end{array}$ & $\begin{array}{l}\text { P.a Jozé Fran.co Cardozo } \\
\text { VM.ce me informe, se julga digno de imprimir-se, a } \\
\text { Epistola de Horacio aos Pisões, traduzida por An- } \\
\text { tonio Jozé de Lima Leitão. D.s G.e a VM.ce B.a a } \\
27 \text { de Abril de } 1818 \text {. Conde da Palma. S.r Proffessor } \\
\text { Jozé Francisco Cardozo. }\end{array}$ \\
\hline $\begin{array}{l}19 \\
\text { IMP }\end{array}$ & $\begin{array}{l}\text { APEB } \\
\text { Seção Colonial/Provincial } \\
\text { Cartas do Governo, maço } 170 \\
(1817-1819), \text { fl. } 255 .\end{array}$ & $\begin{array}{l}\text { P.a o Proffessor Jubilado Jozé Fran.co Cardozo } \\
\text { Informe VM.ce se o livro intitulado Economia da } \\
\text { Vida Humana está em termos de Reimprimir se. D.s } \\
\text { G.e a VM.ce B.a a } 23 \text { de Julho de } 1818 \text {. Conde da } \\
\text { Palma. S.r Proffessor Jozé Francisco Cardozo. }\end{array}$ \\
\hline $\begin{array}{l}20 \\
\text { NPI }\end{array}$ & $\begin{array}{l}\text { APEB } \\
\text { Seção Colonial/Provincial } \\
\text { Cartas do Governo, maço } 170 \\
(1817-1819), \text { fls. } 300-300 v .\end{array}$ & $\begin{array}{l}\text { P.a o Proffessor Jubilado Joze Fran.co Cardozo } \\
\text { Envio a VM.ce os Versos juntos, para que me infor- } \\
\text { me, quanto antes se são dignos de ser impressos. D.s } \\
\text { G.e a VM.ce B.a } 31 \text { de Outubro de } 1818 \text {. Conde da } \\
\text { Palma. S.r Joze Francisco Cardozo. }\end{array}$ \\
\hline \begin{tabular}{|l|}
21 \\
NPI
\end{tabular} & $\begin{array}{l}\text { APEB } \\
\text { Seção Colonial/Provincial } \\
\text { Cartas do Governo, maço } 170 \\
(1817-1819), \text { fl. 328v }\end{array}$ & $\begin{array}{l}\text { P.a o Proffessor Jubilado Joze Francisco Cardozo } \\
\text { Informe, VM.ce, se a Ode Pindarica incluza, esta } \\
\text { nos termos de se poder imprimir. D.s G.e a VM.ce } \\
\text { B.a } 12 \text { de Janeiro de } 1819 \text {. Conde da Palma. S.r Prof- } \\
\text { fessor Joze Francisco Cardozo. }\end{array}$ \\
\hline \begin{tabular}{|l|}
22 \\
IMP
\end{tabular} & $\begin{array}{l}\text { APEB } \\
\text { Seção Colonial/Provincial } \\
\text { Cartas do Governo, maço 172-E } \\
(1819-1820), \text { fl. } 22 .\end{array}$ & $\begin{array}{l}\text { Para o D.r Francisco Carneiro de Campos } \\
\text { Envio a VM.ce a Oração gratulatoria junta, p.a q } \\
\text { me informe, se esta nos tr.os de obter licença p.a ser } \\
\text { impresa. D.s G.e a VM.ce B.a } 22 \text { de Maio de } 1819 . \\
\text { Conde da Palma. Snr. D.or Francisco Carneiro de } \\
\text { Campos. }\end{array}$ \\
\hline \begin{tabular}{|l|}
23 \\
IMP
\end{tabular} & $\begin{array}{l}\text { APEB } \\
\text { Seção Colonial/Provincial } \\
\text { Cartas do Governo, maço 172-E } \\
(1819-1820), \text { fl. } 28 .\end{array}$ & $\begin{array}{l}\text { Para o Proffessor Jubilado Joze Francisco Cardozo } \\
\text { Envio a VM.ce o Manuscripto Manual de Medicina } \\
\text { Pratica, p.a q me informe se merece ser impresso. Ds } \\
\text { Guarde a VM.ce. B.a } 2 \text { de Junho de } 1819=\text { Conde da } \\
\text { Palma = Snr Proffessor Joze Francisco Cardozo }\end{array}$ \\
\hline \begin{tabular}{|l}
24 \\
INE
\end{tabular} & $\begin{array}{l}\text { APEB } \\
\text { Seção Colonial/Provincial } \\
\text { Cartas do Governo, maço 172-E } \\
(1819-1820) \text {, fls. } 38-38 v\end{array}$ & $\begin{array}{l}\text { Para o Proffessor Jubilado J.e Francisco Cardozo } \\
\text { Envio a VM.ce o Manuscripto junto, q contem a de- } \\
\text { scripção junta das Festas Reaes celebradas em Ti- } \\
\text { juco p.a q' me informe se merece ser impresso. D.s } \\
\text { G.e a VM.ce. B.a } 12 \text { de Junho de } 1819 \text { = Conde da } \\
\text { Palma = Snr Proffessor Jubilado J.e Fran.co Cardozo }\end{array}$ \\
\hline
\end{tabular}




\begin{tabular}{|c|c|c|}
\hline $\begin{array}{l}25 \\
\text { NPI }\end{array}$ & $\begin{array}{l}\text { APEB } \\
\text { Seção Colonial/Provincial } \\
\text { Cartas do Governo, maço 172-E } \\
(1819-1820) \text {, fl. } 52 .\end{array}$ & $\begin{array}{l}\text { Para o D.or Fr.co Carn.o de Campos } \\
\text { Envio a VM as Theses de Geometria juntas, para } \\
\text { que me informe, se estão nos termos de se obterem } \\
\text { licença. D. G. a VM. B.a } 2 \text { de Julho de } 1819=\text { Conde } \\
\text { da Palma = Snr D.or Francisco Carneiro de Campos }\end{array}$ \\
\hline $\begin{array}{l}26 \\
\text { NPI }\end{array}$ & $\begin{array}{l}\text { APEB } \\
\text { Seção Colonial/Provincial } \\
\text { Cartas do Governo, maço 172-E } \\
(1819-1820) \text {, fl. 54v. }\end{array}$ & $\begin{array}{l}\text { Para o D.or Francisco Carneiro de Campos } \\
\text { Remetto a VM o Drama junto intitulado = A sen- } \\
\text { sibilidade no crime = para que me informe se está } \\
\text { nos termos de obter licença, para ser impresso. Ds. } \\
\text { Guarde a VM. B.a } 7 \text { de Julho de } 1819=\text { Conde da } \\
\text { Palma = Sr D.or Francisco Carneiro de Campos }\end{array}$ \\
\hline $\begin{array}{l}27 \\
\text { NPI }\end{array}$ & $\begin{array}{l}\text { APEB } \\
\text { Seção Colonial/Provincial } \\
\text { Cartas do Governo, maço 172-E } \\
(1819-1820) \text {, fl. } 62 .\end{array}$ & $\begin{array}{l}\text { Para o D.or Francisco Carneiro de Campos } \\
\text { Envio a VM as Concluzões de Logica junto p.a q' } \\
\text { me informe se estão nos termos de obter licença para } \\
\text { serem impressas. Ds. Guarde a VM. B.a } 13 \text { de Julho } \\
\text { de } 1819=\text { Conde da Palma = Snr. D.or Fran.co Car- } \\
\text { nr.o de Campos. }\end{array}$ \\
\hline $\begin{array}{l}28 \\
\text { NPI }\end{array}$ & $\begin{array}{l}\text { APEB } \\
\text { Seção Colonial/Provincial } \\
\text { Cartas do Governo, maço 172-E } \\
(1819-1820) \text {, fl. 76v. }\end{array}$ & $\begin{array}{l}\text { P.a Joze Fran.co Cardozo } \\
\text { Envio a VM a Comedia sentimental intitulada = Dev- } \\
\text { er e Natureza = p.a q' me informe, se está no termos } \\
\text { de obter licença p.a ser impressa. Ds. Guarde a VM. } \\
\text { B.a } 28 \text { de Julho de } 1819=\text { Conde da Palma = Snr Joze } \\
\text { Francisco Cardozo }\end{array}$ \\
\hline $\begin{array}{l}29 \\
\text { NPI }\end{array}$ & $\begin{array}{l}\text { APEB } \\
\text { Seção Colonial/Provincial } \\
\text { Cartas do Governo, maço 172-E } \\
(1819-1820), \text { fl.173. }\end{array}$ & $\begin{array}{l}\text { Para o D.or Fran.co Carneiro de Campos } \\
\text { Envio a VM as Proposições de Geometria juntas, } \\
\text { p.a q me informe, se estão nas circunstancias de ob- } \\
\text { terem licença p.a se imprimirem. Ds G.e a VM. B.a } \\
16 \text { de Novembro de } 1819 \text {. Conde da Palma. S.r D.or } \\
\text { Fran.co Carneiro de Campos. }\end{array}$ \\
\hline $\begin{array}{l}30 \\
\text { NPI }\end{array}$ & $\begin{array}{l}\text { APEB } \\
\text { Seção Colonial/Provincial } \\
\text { Cartas do Governo, maço 172-E } \\
(1819-1820), \text { fl. } 200 .\end{array}$ & $\begin{array}{l}\text { Para o D.or Fran.co Carneiro de Campos } \\
\text { Envio a VM.ce as Theses Metaphisicas juntas, p.a } \\
\text { q me informe se estão nos termos de se poderem im- } \\
\text { primir Ds G.e a VM.ce. B.a } 14 \text { de Dezembro de } 1819 \\
=\text { Conde da Palma = S.r D.or Francisco Carneiro de } \\
\text { Campos }\end{array}$ \\
\hline $\begin{array}{l}31 \\
\text { NPI }\end{array}$ & $\begin{array}{l}\text { APEB } \\
\text { Seção Colonial/Provincial } \\
\text { Cartas do Governo, maço 172-E } \\
(1819-1820) \text {, fl. } 261 \text {. }\end{array}$ & $\begin{array}{l}\text { Para o Proffessor Jubilado Jozé Fran.co Cardozo } \\
\text { Envio a VM.ce o compromisso junto, p.a q me in- } \\
\text { forme, se esta nos termos de obter licença, p.a ser } \\
\text { impresso. Ds Guarde a VM.ce. B.a } 8 \text { de Março de } \\
1820=\text { Conde da Palma = S.r Proffessor Jubilado } \\
\text { Joze Fran.co Cardozo }\end{array}$ \\
\hline $\begin{array}{l}32 \\
\text { NPI }\end{array}$ & $\begin{array}{l}\text { APEB } \\
\text { Seção Colonial/Provincial } \\
\text { Cartas do Governo, maço 172-E } \\
(1819-1820) \text {, fl. } 278 \text {. }\end{array}$ & $\begin{array}{l}\text { Para o D.or Fran.co Carneiro de Campos } \\
\text { Envio a VM.ce a Falla junta traduzida do Idioma } \\
\text { Inglez, p.a q me informe se está nos termos de se dar } \\
\text { ao prelo. Ds G.e a VM.ce. B.a } 16 \text { de Março de } 1820 \\
\text { = Conde da Palma = Sor D.or Francisco Carneiro de } \\
\text { Campos }\end{array}$ \\
\hline $\begin{array}{l}33 \\
\text { NPI }\end{array}$ & $\begin{array}{l}\text { APEB } \\
\text { Seção Colonial/Provincial } \\
\text { Cartas do Governo, maço 172-E } \\
(1819-1820) \text {, fl 315v. }\end{array}$ & $\begin{array}{l}\text { Para o D.or Fran.co Carneiro de Campos } \\
\text { Envio a VM.ce as Theses Methaphisicas juntas, p.a } \\
\text { q me informe se estão nos termos de obterem licença, } \\
\text { p.a se imprimirem. Ds G.e a VM.ce. B.a } 4 \text { de Maio de } \\
1820=\text { Conde da Palma = S.r D.or Francisco Carnei- } \\
\text { ro de Campos }\end{array}$ \\
\hline
\end{tabular}




\begin{tabular}{|c|c|c|}
\hline $\begin{array}{l}34 \\
\text { NPI }\end{array}$ & $\begin{array}{l}\text { APEB } \\
\text { Seção Colonial/Provincial } \\
\text { Cartas do Governo, maço 172-E } \\
(1819-1820), \text { fl. } 321 \mathrm{v} .\end{array}$ & $\begin{array}{l}\text { Para o D.or Fran.co Carneiro de Campos } \\
\text { Envio a VM.ce a Demonstração junta de Prop- } \\
\text { osição = 146, das Instituições Metaphicas [sic, por } \\
\text { Metaphisicas] de Genuense, p.a q me informe se } \\
\text { está nos termos de obter licença p.a se imprimir Ds } \\
\text { G.e a VM.ce. B.a } 15 \text { de Maio de } 1820=\text { Conde da } \\
\text { Palma = S.r D.or Francisco Carnr.o de Campos }\end{array}$ \\
\hline $\begin{array}{l}35 \\
\text { NPI }\end{array}$ & $\begin{array}{l}\text { APEB } \\
\text { Seção Colonial/Provincial } \\
\text { Cartas do Governo, maço 172-E } \\
(1819-1820), \text { fl. } 346 .\end{array}$ & $\begin{array}{l}\text { P.a o D.or Fran.co Carneiro de Campos } \\
\text { Envio a VM.ce as Theses juntas, p.a q me informe } \\
\text { se merecem licença p.a se imprimirem. Deos G.e a } \\
\text { VM.ce. B.a } 24 \text { de Junho de } 1820=\text { Conde da Palma } \\
\text { S.r D.or Franc.co Carneiro de Campos }\end{array}$ \\
\hline $\begin{array}{l}36 \\
\text { NPI }\end{array}$ & $\begin{array}{l}\text { APEB } \\
\text { Seção Colonial/Provincial } \\
\text { Cartas do Governo, maço 172-E } \\
(1819-1820) \text {, fl. } 349 .\end{array}$ & $\begin{array}{l}\text { P.a o D.or Francisco Carneiro de Campos } \\
\text { Envio a VM.ce a Carta manuscrita junta, á qual se } \\
\text { pedem licença p.a imprimirem Cristo, Bastos e Fil- } \\
\text { gueiras, Directores da Comp.a de seguros d'esta } \\
\text { Praça, denominada = Conceito Publico = ao fim } \\
\text { de me informe se está nos termos de obter a dita } \\
\text { licença. Ds G.e a VM.ce. B.a } 22 \text { de Junho de } 1820= \\
\text { Conde da Palma = S.r D.or Franc.co Carneiro }\end{array}$ \\
\hline $\begin{array}{l}37 \\
\text { NPI }\end{array}$ & $\begin{array}{l}\text { APEB } \\
\text { Seção Colonial/Provincial } \\
\text { Cartas do Governo, maço } 173 \\
(1820-1821), \text { fl. } 3 .\end{array}$ & $\begin{array}{l}\text { P.a o Proffessor Jubilado Jozé Fran.co Cardozo } \\
\text { Envio a VM.ce as Thezes juntas, p.a q me informe, } \\
\text { se estão nos termos de se imprimirem. Ds G.e a } \\
\text { VM.ce. B.a } 24 \text { de Julho de } 1820=\text { Conde da Palma } \\
=\text { S.r Proffessor Jubilado Joze Francisco Cardozo de } \\
\text { Moraes }\end{array}$ \\
\hline $\begin{array}{l}38 \\
\text { IMP }\end{array}$ & $\begin{array}{l}\text { APEB } \\
\text { Seção Colonial/Provincial } \\
\text { Cartas do Governo, maço } 173 \\
(1820-1821), \text { fl. } 19 .\end{array}$ & $\begin{array}{l}\text { P.a o D.or Fran.co Carneiro de Campos } \\
\text { Informe VM.ce, se a Oração de Ação de Graças jun- } \\
\text { ta está nos termos de ser impressa. Ds G.e a VM.ce. } \\
\text { B.a } 12 \text { de Agosto de } 1820=\text { Conde da Palma = S.r } \\
\text { D.or Franc.co Carneiro de Campos }\end{array}$ \\
\hline $\begin{array}{l}39 \\
\text { NPI }\end{array}$ & $\begin{array}{l}\text { APEB } \\
\text { Seção Colonial/Provincial } \\
\text { Cartas do Governo, maço } 173 \\
(1820-1821), \text { fl. } 36 .\end{array}$ & $\begin{array}{l}\text { P.a o D.or Fran.co Carneiro de Campos } \\
\text { Envio a VM.ce o Manuscripto junto, q contem huma } \\
\text { Demonstração Explicativa Filosophica, p.a q me } \\
\text { informe se está nos termos de se dá ao prelo por meio } \\
\text { da Imprensa. Ds G.e a VM.ce. B.a } 31 \text { de Agosto de } \\
1820=\text { Conde da Palma = S.r D.or Francisco Carnei- } \\
\text { ro de Campos }\end{array}$ \\
\hline $\begin{array}{l}40 \\
\text { NPI }\end{array}$ & $\begin{array}{l}\text { APEB } \\
\text { Seção Colonial/Provincial } \\
\text { Cartas do Governo, maço } 173 \\
(1820-1821), \text { fl. 58v. }\end{array}$ & $\begin{array}{l}\text { P.a o Proffessor Jubilado Jozé Fran.co Cardozo } \\
\text { Envio a VM.ce o Catalogo junto de livros Francez- } \\
\text { es, e Portuguezes, p.a q me informe, se está nos ter- } \\
\text { mos de se poder imprimir. Ds G.e a VM.ce. B.a } 28 \\
\text { de } 7 . \text { bro de } 1820=\text { Conde da Palma = S.r Proffessor } \\
\text { Jubilado Joze Francisco Cardozo. }\end{array}$ \\
\hline $\begin{array}{l}41 \\
\text { NPI }\end{array}$ & $\begin{array}{l}\text { APEB } \\
\text { Seção Colonial/Provincial } \\
\text { Cartas do Governo, maço } 173 \\
(1820-1821) \text {, fl. } 67 .\end{array}$ & $\begin{array}{l}\text { P.a o D.or Francisco Carneiro de Campos } \\
\text { Envio a VM.ce o Manuscripto junto intitulado = } \\
\text { Manual do Systema da Sociedade da Escola Bri- } \\
\text { tanica e Estrangeira de Londres = ao fim de q me } \\
\text { informe, se merece obter licença p.a ser impressa. Ds } \\
\text { G.e a VM.ce. B.a } 6 \text { de } 8 \text { bro de } 1820=\text { Conde da Pal- } \\
\text { ma = S.r D.or Franc.co Carno de Campos }\end{array}$ \\
\hline
\end{tabular}




\begin{tabular}{|c|c|c|}
\hline $\begin{array}{l}42 \\
\text { NPI }\end{array}$ & $\begin{array}{l}\text { APEB } \\
\text { Seção Colonial/Provincial } \\
\text { Cartas do Governo, maço } 173 \\
(1820-1821) \text {, fl. 105v. }\end{array}$ & $\begin{array}{l}\text { P.a o D.or Fran.co Carneiro de Campos } \\
\text { Envio a VM.ce as Theses juntas, p.a q examinando } \\
\text { as me informe com a brevide, q lhe for possivel, se } \\
\text { estão nos termos de ser impressas. Ds G.e a VM.ce. } \\
\text { B.a } 5 \text { de Dezbr.o d' } 1820=\text { Conde da Palma = S.r D.or } \\
\text { Franc.co Carneiro de Campos }\end{array}$ \\
\hline $\begin{array}{l}43 \\
\text { IMP }\end{array}$ & $\begin{array}{l}\text { APEB } \\
\text { Seção Colonial/Provincial } \\
\text { Cartas do Governo maço } 173 \\
(1820-1821) \text {, fl. } 121 .\end{array}$ & $\begin{array}{l}\text { P.a o D.or Fran.co Carneiro de Campos } \\
\text { Envio a VM.ce a Pastoral junta do Bispo Eleito } \\
\text { do Pará, p.a q me informe, se está nos termos de ser } \\
\text { impressa.Ds. G.e VM.ce B.a } 3 \text { de Janeiro de } 1821 . \\
\text { Conde da Palma. S.r D.r Francisco Carneiro de Cam- } \\
\text { pos. }\end{array}$ \\
\hline $\begin{array}{l}44 \\
\text { IMP }\end{array}$ & $\begin{array}{l}\text { APEB } \\
\text { Seção Colonial/Provincial } \\
\text { Cartas do Governo, maço } 173 \\
(1820-1821) \text {, fl. } 126 .\end{array}$ & $\begin{array}{l}\text { P.a o Proffessor Jubilado Jozé Fran.co Cardozo } \\
\text { Remetto a VM.ce o Discurso junto manuscripto, } \\
\text { p.a q me informe, se está nos termos de se dar licença. } \\
\text { Ds G.e a VM.ce. B.a } 11 \text { de Janr.o de } 1821=\text { Conde } \\
\text { da Palma = S.r Proffessor Jubilado Joze Francisco } \\
\text { Cardozo. }\end{array}$ \\
\hline
\end{tabular}

